\title{
Surgical Management of Parkinson's Disease: The Role of Lesioning Procedures in Developing Countries in the Modern Era
}

\author{
Sameh Abdelbari ${ }^{1 *}$ (D), Bassem Mohamed Ayoub ${ }^{1}$, Hanan Abdallah Amer ${ }^{2}$, Ramy Kamel ${ }^{1}$ (D) \\ ${ }^{1}$ Department of Neurosurgery, Kasr Alainy Faculty of Medicine, Cairo University, Cairo, Egypt; ${ }^{2}$ Department of Neurology, Kasr \\ Alainy Faculty of Medicine, Cairo University, Cairo, Egypt
}

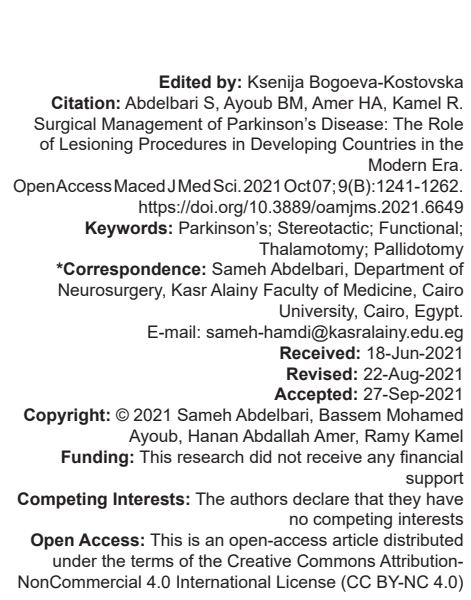

\section{Introduction}

\section{Background and rationale}

Parkinson's disease (PD) is a progressive neurodegenerative disorder characterized by loss of dopaminergic neurons of the substantia nigra pars

\begin{abstract}
BACKGROUND: The known loss of dopaminergic cells in the pars-compacta of the substantia nigra that is the hallmark of Parkinson's disease (PD). The cellular pathophysiology of the motor dysfunction is beginning to be better understood, thereby providing a stronger scientific rationale for surgical interventions. Yet, to date, there are no treatments that prevent, halt, or cure PD. Surgical strategies, offer symptomatic relief or control of motor complications associated with drug treatment. Both pallidotomy and thalamotomy were extensively used in the treatment of PD in the1950's and 1960's. With the introduction of levodopa (L-dopa) in the1960's and the realization of its striking benefits, surgery was almost abandoned and used only for patients with severe tremor. Surgical therapy is now being used earlier and more often. There are currently three brain regions being considered as targets for functional neurosurgery for PD (other than transplantation) either central nervous system lesions (thalamotomy, pallidotomy, or subthalamic nucleus [STN] lesions) or deep brain stimulation. These targets are: The ventral intermediate nucleus of the thalamus, the internal segment of the Globus Pallidus, and the STN.
\end{abstract}

AIM: The objective of the study was to assess the outcome ( 3 months and 6 months) of lesioning procedures in PD patients meeting the inclusion criteria.

METHODS: A prospective clinical study conducted on ten idiopathic PD (IPD) patients during the period from October 2018 to March 2021 at Cairo University Hospitals. This study was concerned to improve the motor symptoms of IPD patients by stereotactic radiofrequency ablative procedures. Cases were restricted to ten patients due to the COVID19 pandemic and restriction of elective cases for chronic patients at Cairo University hospitals.

RESULTS: In our study, we operated on ten IPD patients who were meeting our selection criteria by ablative procedures contralateral to Parkinsonian symptoms. Age of the patients ranged 17-70 years with mean of 50.5 \pm 16.35 y with predominance in males representing six patients. Mean duration of PD according to history ranged from 2 to 12 year with mean of $8 \pm 3.1$ years. Patients were divided into three groups according to their presentation and the operation done for them. Thalamotomy group: Preoperatively, the Unified PD Rating Scale (UPDRS) III off and on, respectively, was $24.4 / 15.2$ and postoperatively was $13 / 7.4$ with improvement $47 \% / 51 \%$. The tremor subscore was $5.4 / 2.8$ preoperatively and $1.4 / 0.8$ postoperatively with average of $72 \%$ improvement. The UPDRS I pre was $17.2 / 11.6$ and post it became $10.6 / 7$ with $39 \%$ improvement modified $\mathrm{H}$ \& Y $2.4 / 1.7$ pre and postoperatively (29\% improvement). Pallidotomy group: Preoperatively, the UPDRS III off and on, respectively, was 38.5/23.5 and postoperatively was $28 / 16$ with improvement $27 \% / 32 \%$. The rigidity subscore was $5 / 2.5$ preoperatively and $2 / 1$ postoperatively with average of $60 \%$ improvement. The bradykinesia subscore was $9 / 5.5$ preoperatively and $5.5 / 2.5$ postoperatively with average of $47 \%$ improvement. The dyskinesia subscore was 4.5 preoperatively and 1.2 postoperatively with average of $71 \%$ improvement. The UPDRS II pre was $22 / 12.5$ and post it became 16/10 with $25 \%$ improvement modified H \& Y $2.75 / 2.25$ pre \& postoperatively (18\% improvement). Combined group: Preoperatively, the UPDRS III off \& on respectively was $41.33 / 28.67$ and postoperatively was $15.67 / 11.33$ with improvement $62 \% / 60 \%$. The rigidity subscore was $5 / 3.33$ preoperatively and $1.67 / 1$ postoperatively with average of $68 \%$ improvement. The bradykinesia subscore was $10 / 6$ preoperatively and $4 / 1.33$ postoperatively with average of $72 \%$ improvement. The UPDRS II pre was $28.33 / 19.33$ and post it became $16.33 / 10.67$ with $43 \%$ improvement modified $\mathrm{H}$ and $\mathrm{Y} 2.83 / 2$ pre and post-operatively (29\% improvement). Postoperatively, there was a high significant statistical finding in all clinical score and subscore of Parkinsonian symptoms.

CONCLUSION: The study concludes that lesioning procedure should be revisited globally using the modern techniques of targeting and controlled thermal lesion protocols guided by capsular somatotopy and intraoperative macroelectrode stimulation, that will improve the outcome dramatically. Ablative procedures proved their efficacy in controlling motor symptoms of IPD and their cost-benefit in low and middle-income nations. compacta. This neuronal loss results in decreased dopaminergic innervation of the striatum, most prominent in the dorsal putamen.

Clinically, PD is characterized by the presence of bradykinesia, rigidity, and tremor. The tremor is typically a $3-4 \mathrm{~Hz}$ resting tremor, but it may also include lower amplitude postural and kinetic components. 
About $30 \%$ of patients with PD do not have tremor, but one needs to be more cautious about the diagnosis in these individuals. PD is usually asymmetric with one side being affected first and remaining worse throughout the course of the disease.

Non-motor symptoms are increasingly recognized as a source of disability in $\mathrm{PD}$, and some of these can occur at any time during the course of the disease, such as depression and anxiety, fatigue, sleep disturbances, and autonomic dysfunction [1].

Before the introduction of Levodopa as a medical the treatment of PD in the mid-1960s, the earlier era was an outstanding era for ablative surgery for movement disorders and followed the earlier introduction of the stereotactic frame and targeting methods of the basal ganglia and thalamus for treatment of PD, dystonia, or tremor. This era came to an end after the introduction of levodopa and due to the negative reputation of the excesses of psychosurgery in that period.

However, the stereotactic surgery regained attention back in the 1990s. Functional surgery is accepted again as one of the treatment modalities for movement disorders [2].

Different articles demonstrated the value of stereotactic neurosurgery especially thalamotomy in the treatment of PD, microelectrode recording (MER), first used in the 1960s, by Guiot and Narabayashi made it possible to define the ventral intermediate (VIM) nucleus of the thalamus and determine that it was the best target to control the tremor in PD. However, thalamotomy provided a little improvement of the hypokinetic element of PD. This gave a rationale for combining pallidotomy (which improves hypokinetic symptoms and levodopa motor compilations) with thalamotomy, where the second target would be listened only if necessary, depending on the response to the initial lesion [3].

Recent literature identified the subthalamic nucleus (STN) as a potential new target; lesioning of the STN was initially believed to be too risky for humans [2]. Subthalamotomy to relieve Parkinsonian symptoms such as tremor and rigidity was also explored beginning in the 1960s and 1970s, although the exact STN itself was rarely targeted, instead the subthalamic connections were targeted [3].

Approaching the end of the 1980s, Benabid et al. made the important discovery that chronic electrical high-frequency stimulation (deep brain stimulation [DBS]) of various basal ganglia targets is as effective as lesioning for the treatment of different movement disorders. Soon thereafter, the use of DBS at the promising new target, the STN target for PD was studied. Results showed that STN DBS is a highly effective treatment for PD. Since then, STN DBS became the standard surgical treatment for patients with advanced $\mathrm{PD}$, in particular those with drug-induced complications or drug-resistant tremor. Following the success of STN DBS for PD, DBS has also been used successfully in patients with either primary dystonia or with dystonia as a manifestation of PD, targeting primarily the Globus Pallidus (GPi) [2].

For most of the $20^{\text {th }}$ century and increasingly so in the $21^{\text {st }}$ century, functional procedures have remained integral to the neurosurgical armamentarium, allowing the treatment of many pathologies, including epilepsy, PD, other movement disorders, pain syndromes, and some psychiatric disorders. However, functional surgeries may require particularly extensive and expensive resources, creating a barrier to the adoption of functional techniques for low- and middleincome countries (LMIC) that are home to the majority of the five-billion people lacking access to safe surgical care [4].

A recent worldwide analysis determined that five-million individuals suffering from treatable "essential neurosurgical cases" will never undergo the indicated procedure, also finding that most of these cases will occur in Africa or Southeast Asia [5]. It is easy to extrapolate that surgeons with sub-specialty training in functional and stereotactic "non-essential" techniques, such as for movement disorders, are in even greater demand. Advanced technologies that are readily found in high income countries are also lacking in LMIC, making performing functional neurosurgery difficult in these regions. Therefore, to bring about the most effective treatment of myriad neurological diseases that can effectively be treated by functional neurosurgery, the standardization of techniques within specific resource contexts may facilitate wider global implementation.

\section{Rationale of study}

The economic downturns that hit the world in the past few years had their highest impact on developing countries. The tough economic situation and reduction in services like health insurance may not allow a fair and equal opportunity of treatment to all citizens. Developing nations now struggle with large scale conflicts, income inequality, poverty, food, and water security and lack of economic opportunity and employment all of which play an important role in the development of the health sector in those nations.

Through the last century the field of functional and stereotactic neurosurgery had a great evolution in all aspects rendering this field a real state of art. Medicine in general and neurosurgery in particular targeted saving patients' lives as the main priority of management, later on with the improvement of both understanding of neurophysiology and operative techniques the concept of improving the quality of life emerged. Many procedures aim now for improving the patients' quality of life through alleviating pain or enhancing the functional capacity of the patients. 
However, these procedures commonly are very expensive and highly sophisticated.

It would be unfair to quit treating those patients with these "non-essential" neuro-pathologies if compared to trauma or cerebrovascular diseases due to the high cost of the DBS device and later on battery changing. Improving these patients' quality of life can be achieved via lesioning procedures which are not essentially equivalent to DBS, but results can be compare to it.

Disadvantages of DBS include: Stimulators are bulky and can be uncomfortable for the patient. Stimulators require regular adjustment especially in the early months after insertion. Stimulator units need to be replaced every 3-5 years (for non-rechargeable types). Lesions do not have these problems, but unlike stimulators, side effects may not be reversible. Other disadvantages of lesioning include: Complications of a lesion cannot be switched off, their beneficial effect may begin to wane and lesions can't be adjusted.

Nevertheless, placement and maintenance of bilateral stimulators are an expensive option both financially and in the time a neurologist will need to spend adjusting the parameters postoperatively; these problems make it inconceivable that the implantation of bilateral deep brain stimulators into STN, for example, could be a viable option for any but a few of the millions of patients worldwide who suffer from movement disorders [6].

\section{Patients and Methods}

\section{Patients selection}

Study design

This is a prospective clinical study.

This study was concerned to improve the motor symptoms of idiopathic PD (IPD) patients by stereotactic radiofrequency ablative procedures. The study was conducted during the period from October 2018 to March 2021 at Cairo University Hospitals. The last two patients had only 4 months post-operative follow-up.

\section{Patient selection}

During that period, 70 Parkinson's patients were examined at the outpatient clinic; only 25 patients with IPD met the selection criteria and were selected to undergo surgery to control their motor symptoms. Due to the COVID-19 pandemic, we had to postpone all elective cases at our department; this led us to performing surgeries on ten patients only during the mentioned time frame (Figure 1).
Figure 1: Diagram showing patients selection process

\section{Inclusion criteria}

The following criteria were included in the study:

- Patients with IPD who had previous good response to levodopa and still responding but with increased dosage and/or frequency

- Levodopa associated dyskinesias, on/off phenomenon, and levodopa intolerable side effects or severe disabling tremors

- $\quad$ Patients with age $\leq 80$ years as long as general condition allows surgery

Patients not experiencing dementia or psychiatric symptoms that are not related to drug intake.

\section{Exclusion criteria}

The following criteria were excluded from the study:

- $\quad$ Patients with no or poor response to L-dopa

- $\quad$ Patients with severe comorbidity from other medical problems (severe uncontrolled DM or HTN)

- $\quad$ Bed ridden patients or severely handicapped patients in whom functional improvement will not be achieved

- $\quad$ Patients with secondary parkinsonism, atypical parkinsonism or Parkinson plus

- Patients with severe cognitive impairment (e.g., dementia) after psychological and psychometric tests as Mini Mental State Examination (MMSE) (Appendix)

Patients with severe speech affection.

\section{Evaluation Methods}

Unified PD Rating Scale (UPDRS) (old version 1999) motor subsets (part 3) and activity of daily living (part 2) (Appendix) 
- Modified $\mathrm{H}$ and $\mathrm{Y}$ stage pre and post (Appendix)

- Motor subscore sometime are more representative of patient major problems like tremors (questions 16, 20, and 21), rigidity (Q 22 and 28) and bradykinesia (Q 23-27, 29, and 31). Total score of each subset will be calculated then the mean will be calculated to get an overall Impression on each subscore.

\section{Ethical statement}

All participants gave their signed written informed consent (Appendix).

The study was approved by the ethical committee of the neurosurgery department and Kasr Al-Aini faculty of medicine, Cairo University.

\section{Clinical evaluation}

Assessments were conducted by both neurologist and neurosurgeon specialized in movement disorders. Assessment schedule was: Pre-operative, immediate post-operative, 2 weeks after discharge to remove sutures, 3 months and 6 months.

1. Neurological evaluation: To ensure that the patient is meeting our selection criteria.

Clinical evaluation was carried out by means of the UPDRS (Appendix). Videotaped examinations were also done for clinical documentation and monitoring of long-term outcome

2. Neurosurgical evaluation: Our main role would be: Re-assessment of the patient's condition and ensuring the diagnosis, assessment of fitness for surgery, family counseling, and choosing an appropriate target. During this meeting, we discussed with the patient the preoperative process and the surgical options, including the available targets and methodologies and a detailed review of the risks and realistic goals of surgery, and then patient informed consent was taken. Patient expectations must be realistic and discussed early in the process to correct any false expectations by patients or family members which could be a reason for surgery failures. The risks associated with a procedure which was discussed with the patients and their relatives were the occurrence of intracerebral hemorrhage, infection, neurological deficits, or seizures. In addition, general contraindications to surgery were explored to make sure that the patient is fit for surgery.

Important information that we emphasize during the meeting include:

- Emphasize that the patient will not stop the medications postoperatively but dosage and frequency will decrease

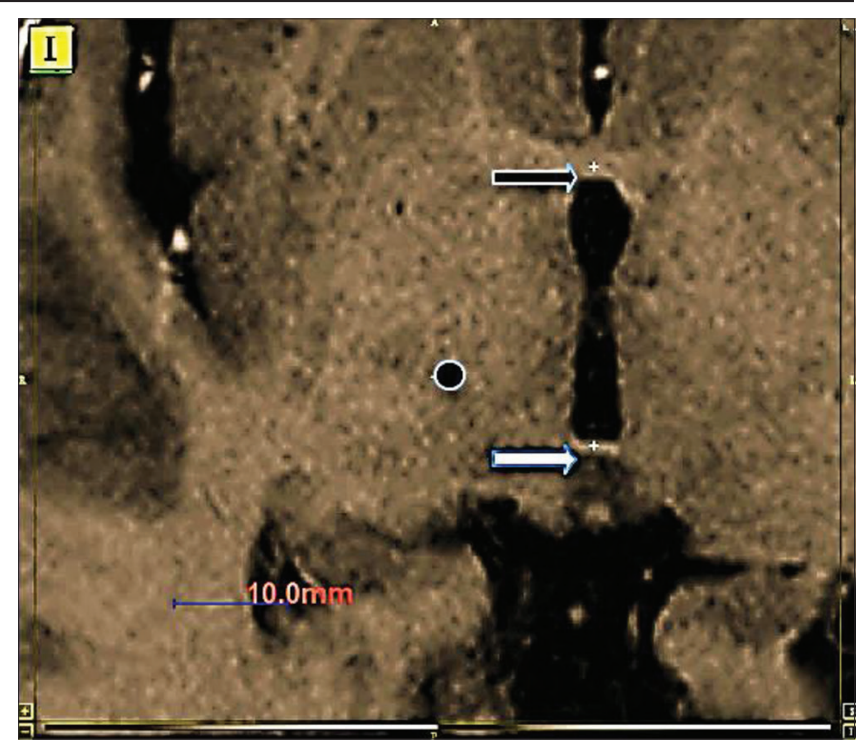

Figure 2: Magnetic resonance imaging axial-cut showing anterior commissure (AC) (Black arrow), posterior commissure (PC) (White arrow), ventral intermediate (Black circle) is located according to coordinates $14 \mathrm{~mm}$ lateral, $6 \mathrm{~mm}$ anterior to $P C$, at the AC-PC plane

- $\quad$ The effect of the lesion may wane by time due to the progressive nature of the disease

- The most recent surgical management is DBS; however, till the end of this study, it was not supported by the government insurance.

3. Neuroimaging

Pre-operative imaging, preferably magnetic resonance imaging (MRI), was considered mandatory in patients being evaluated for surgery. In general, exclude the presence of structural lesions or anatomic distortions that might either interfere with proper targeting (e.g., areas of encephalomalacia) or represent an increased risk for hemorrhage (e.g., abnormally enlarged lateral ventricles, severe brain atrophy). In addition, when the diagnosis of IPD was under scrutiny, MRI shows abnormalities typical of multiple system atrophy or progressive supranuclear palsy, which would be a contraindication to surgery. The MRI sequence would also be used for planning and target selection according to the desired procedure.

4. Anesthesia check-up.

\section{Surgical procedure for ablative surgeries}

\section{Target determination}

Patients with tremor dominant (by symptoms and UPDRS score) PD were offered VIM nucleus (unilateral or bilateral) as a target (Figure 2) while those whose main problem was bradykinesia, rigidity or levodopa induced dyskinesia (by symptoms and UPDRS) received posteroventral GPi internus (unilateral or bilateral) as a target (Figure 3). Patients with asymmetrical symptoms were selected for unilateral surgery to improve disability in the more affected limb or the side of patients' preference. 


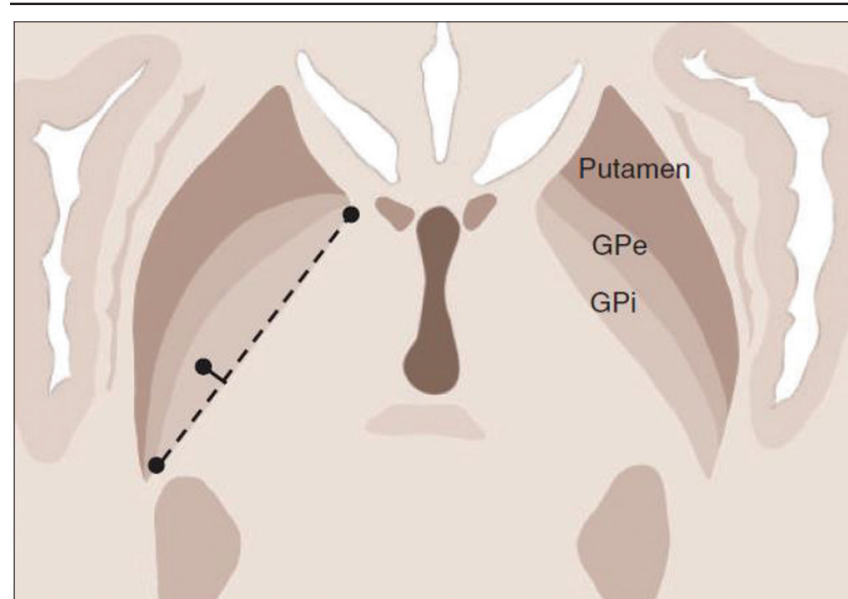

Figure 3: The axial cut at the midcommissural plane. The medial border of the GPi is split into thirds (dashed line) and a point 3-4 mm lateral and perpendicular to the line at the junction of the posterior one third and anterior two thirds (short vertical bar with black dot) is used for targeting

\section{Surgical technique}

The patient is admitted 1 or 2 days before surgery. Patient has ordinary pre-operative lab work (CBC, INR, RFTs and LFTs) and anesthesia check-up, although the operation is done by local anesthesia.

Pre-operative images are done in the form of high-resolution Brain MRI on a DICOM format to perfectly localize anterior commissure-posterior commissure plane (AC-PC plane and to visualize different targets. A thin-cut computed tomography (CT) brain in a DICOM format to visualize the AC-PC plane in the event of high artifacts in the stereotactic CT masking the plane.

Medications were withheld overnight before surgery to ensure the patient was in a relative "off" state to maximize the involuntary movement during surgery, to monitor the improvement of the condition during surgery, and to facilitate assessment of the clinical effects during the surgical procedure.

Placement of a stereotactic frame (CRW/BRW Stereotactic System; Radionics, Inc., Burlington, MA or Leksell type G frame, Elekta, Stockholm, Sweden) is done using local anesthetics or scalp block in the operation room making sure that the frame is balanced and the frontal pins are inserted above the later third of eye brow not medial to avoid supraorbital nerve or lateral in temporalis muscle. The next step was the stereotactic high-resolution CT. This was a $0.75-1$ $\mathrm{mm}$-axial scan starting from the infraorbital level to the vertex with no gantry tilt. Contrast enhancement for the CT scan was used occasionally to improve the fusion process (Figure 4).

Target coordinates were determined with the assistance of the StealthStation surgical navigation system of Medtronic and WayPoint ${ }^{\mathrm{TM}}$ Navigator Software of FHC in which images can be fused and
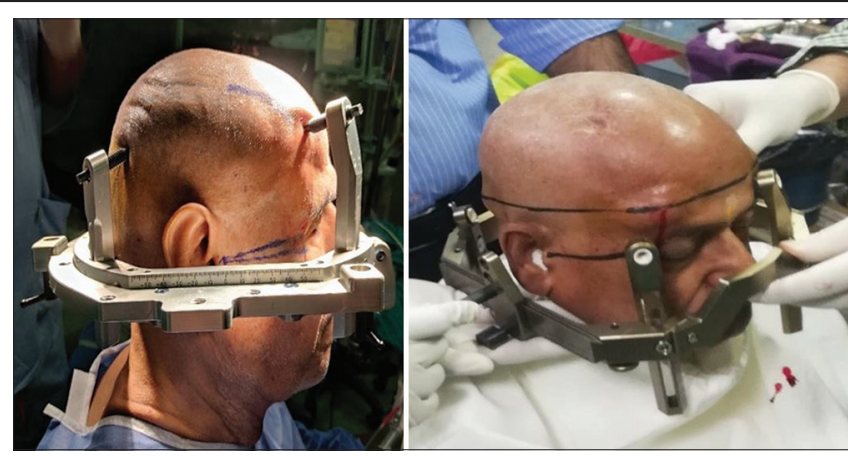

Figure 4: Patient with CRW frame (left) and Leksell frame (right) fixed on the head parallel to the anterior commissure-posterior commissure plane line

reformatted to parallel the AC-PC plane and displayed in different orthogonal views (Figure 5).

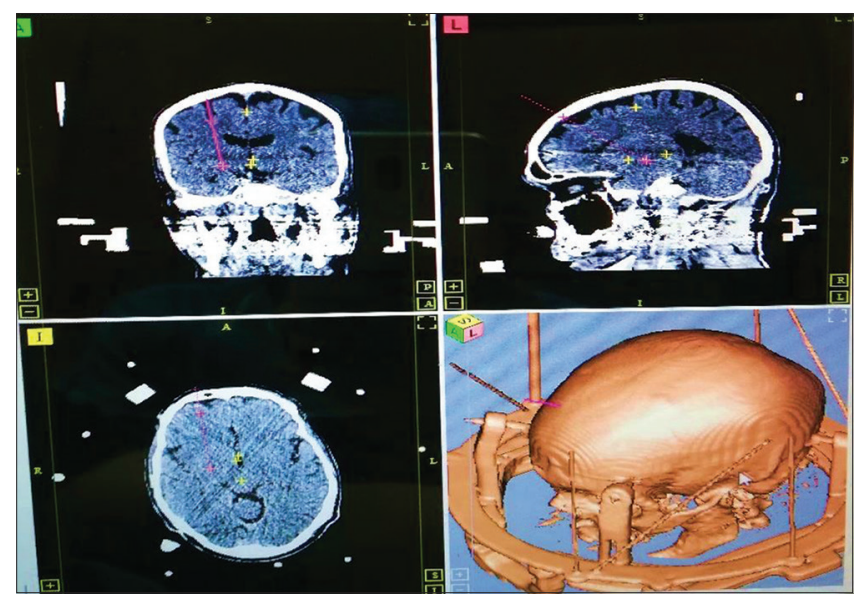

Figure 5: Axial, coronal, and sagittal magnetic resonance imaging T1 Wi while target coordinates and entry point were determined with the assistance of the surgical navigation software

The initial pallidal target was chosen to be 2-4 mm in front of the mid-commissural point, 3-6 mm below the inter-commissural line, and $18-22 \mathrm{~mm}$ lateral to the midline of the third ventricle in the posteroventral medial GPi internus (Figure 3). While the initial thalamic target was taken $25 \%$ of the AC-PC distance in front of the PC 13-15 mm lateral to the midline and at the same horizontal plane as the AC-PC line, adjustments were made depending on the relative size and dimensions of the head, the width of the third ventricle, and the location of the posterior limb of the internal capsule (Figure 2).

\section{Positioning and skin incision}

The patient was positioned in the supine position, with the head elevated slightly. (To avoid brain shift and air embolism) We separated the sterile and non-sterile area around the patient to allow adequate simultaneous surgery and patient testing (Figure 6). After application of local anesthesia, the frontal skin was incised and a pre-coronal burr hole was made. The position of the burr hole was determined by stereotactic guidance. (In general, $1.5-3 \mathrm{~cm}$ off midline, $1-3 \mathrm{~cm}$ anterior to the coronal suture, angle $<13^{\circ}$ is better 
for thalamotomy, i.e., near to vertical, in pallidotomy we prefer also near vertical trajectory, avoid transventricular trajectories). Subsequently, a durotomy and corticectomy were performed. Special attention was paid to penetrate the brain through a gyrus and not a sulcus, when the trajectory was planned.

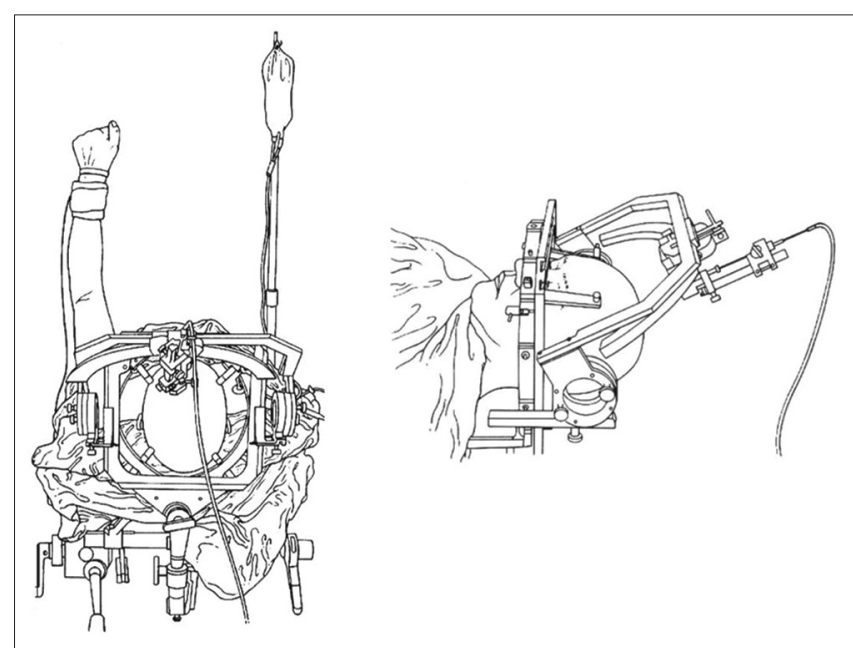

Figure 6: Intra-operative setting allowing simultaneous assessment and lesioning

\section{Dynamic impedance monitoring}

Impedance recording is done when introducing the RF electrode till it reaches the desired target. Impedance recording needs only RF electrode connected to the RF lesion generator and the latter connected with the ground cable. Impedance monitoring does not require extra equipment or added time. Electrical impedance is the measurement of tissue resistance to the alternating current and is measured in Ohm $(\Omega)$. The variation of electrical impedance while the electrode travels through the trajectory is more important than static measurement and called dynamic impedance measurement. Impedance is highest in white matter, lower in CSF and intermediate in grey matter. (e.g., 616, 455 , and $166 \Omega$ ). Impedance values are fairly indicative of the type of tissue around the tip of the electrode, its better as a warning sign that the electrode penetrated into CSF space or white matter. Pallidal target:The electrode passes through white matter then grey matter, so decline in impedance is noticed. If another rise is noticed then internal capsule probably entered again. If a major decline is noticed, then CSF cistern between pallidum and amygdala maybe violated.

Thalamic target: Electrode penetrates the head of caudate then white matter then thalamic nuclei, if the electrode exits the thalamus another rise would occur as it will pass through white matter.

\section{Intraoperative macrostimulation}

Macrostimulation was used to confirm the optimal target location. Low frequency stimulation (2-msec square-wave pulse, $2 \mathrm{~Hz}, 0-5 \mathrm{~V}$ ) was used to obtain motor thresholds to assess the proximity to the internal capsule. Facial contraction or finger movement under low current amplitude meant that the target was too close to the internal capsule and vice versa. High frequency stimulation (2-msec square wave pulses, 50-75 Hz, 0-5 V) was used to assess proximity to ventrocaudal thalamic nucleus and to the optic. Speech function was also evaluated from volume, articulation, and fluency.

Adjustments of the final target were determined after integrating information about alleviation of symptoms and undesired effects. Then trajectory was planned to the best target point. Vim thalamotomy and we use it as a guide during macrostimulation.

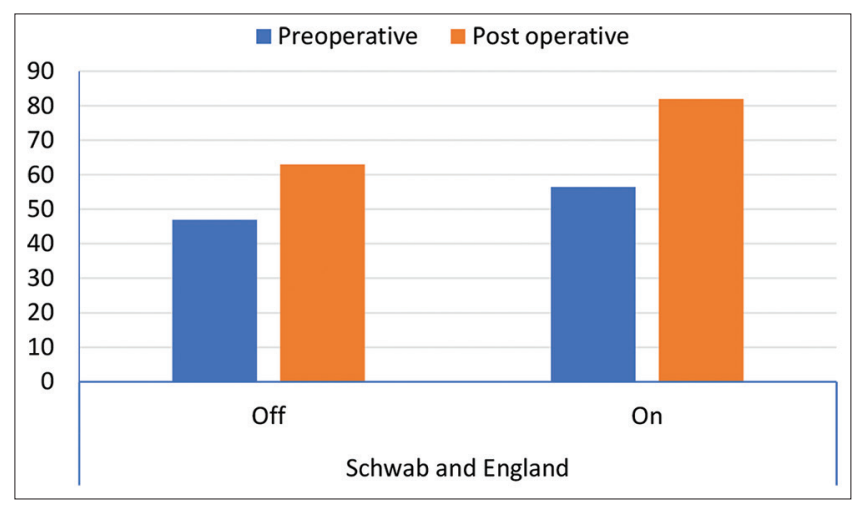

For thalamotomy we test for capsular signs especially in the limbs, sensory side effects in the form of tingling and numbness mainly in the face and tips of fingers, contralateral numbness in the tips of fingers that fade away after $30-60 \mathrm{~s}$ is a good sign for localization of the Vim.

For pallidotomy, we test for optic tract stimulation by perception of flashes of lights, sensory stimulation yields increase of tone, capsular stimulation is mainly in the mouth and tongue.

\section{Radiofrequency lesion}

Once the target location was verified, a temporary test lesion was made at $55^{\circ} \mathrm{C}$ for $10 \mathrm{~s}$. If there were no deficits, a permanent lesion was made at $70-80^{\circ} \mathrm{C}$ for 60 $\mathrm{s}$. The commonly used RF generator was the radionics RF generator illustrated in Figure 7 . The probe used is Monopolar electrode, length $300 \mathrm{~mm}$, Diameter $1.8 \mathrm{~mm}$, Active tip $3 \mathrm{~mm}$, Manufactured by radionics.

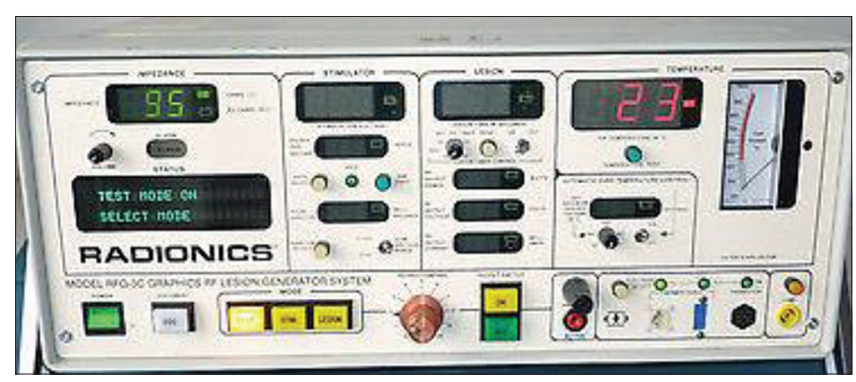

Figure 7: Radionics RF generator 


\section{Post-operative follow-up evaluation}

Follow-up C.T. brain scan was done to the patient immediate post-operative to make sure that there was no hemorrhage and to assess the site and size of the lesion. Most patients were discharged home a day after surgery. Our protocol is to discharge the patient on the same doses of pre-operative medications and to refer them to our colleagues in neurology clinic to modify the doses.

Patient was examined after 2 weeks of surgery to check the wound and remove stitches. Then, the follow-up schedule would be after 3 and 6 months. UPDRS II, III, and modified $\mathrm{H}$ and $\mathrm{Y}$ scale were recorded both pre and post-operative.

\section{Data management and statistical analysis}

\section{Statistical methods}

Data were coded and entered using the Statistical Package for the Social Sciences (SPSS) version 26 (IBM Corp., Armonk, NY, USA). Data were summarized using mean and standard deviation for quantitative variables. Comparisons between preoperative and post-operative data were done using paired t-test (Chan, 2003). $p<0.05$ was considered as statistically significant.

\section{Results}

\section{Demographic Data (Table 1)}

In our study, we operated on ten IPD patients who were meeting our selection criteria by ablative procedures contralateral to Parkinsonian symptoms. Age of the patients ranged 17-70 years with mean of $50.5 \pm 16.35$ years with predominance in males representing 6 patients. Mean duration of PD according to history ranged from 2 to 12 years with mean of $8 \pm 3.1$ years. The disease was mainly bilateral asymmetrical with the right side being the more affected and the procedure done was more common on the left side. (In cases of slight asymmetry, we left the decision for the patient to choose which side to be improved). We performed Thalamotomy alone for tremor predominant Parkinson's with minimal rigidity or bradykinesia, and pallidotomy alone for L-dopa dyskinesia, bradykinesias, or rigidity predominant types of PD. As we mentioned before, the determination of tremor predominant or rigidity predominant was made according to complaint and UPDRS motor subsets. We performed combined pallidotomy and thalamotomy (when mentioned in our study, combined means Vim and GPi on the same side) in patients with combined symptoms. We performed three bilateral cases (when mentioned in our study, bilateral means either both Vim or both GPi), one of them was staged bilateral pallidotomy, the second was bilateral staged pallidotomy and thalamotomy, and the last one was staged bilateral crossed pallidotomy and thalamotomy (when mentioned in our study, crossed means GPi on a side, and Vim on the contralateral side). UPDRS assessment of the patients is done in both periods on and Off period, mean UPDRS III for motor symptoms preoperatively was 28.8 and 17.75 for Off/ On respectively (41\% improvement with L-dopa). Motor subscore sometime are more representative of patient major problems like tremor subscore was 5.5/2.65 for Off/On preoperative. Mean rigidity subscore was $4 / 2.05$, bradykinesia subscore was $7 / 3.9$, and postural instability/Gait disorder subscores were 3.1/1.9. Note that for patient selection it is recommended that there is difference $>30 \%$ improvement between ON/OFF symptoms scoring. UPDRS IV for L-dopa side effects for patient with L-Dopa induced dyskinesia was 2.4. Mean UPDRS II score for daily life habits was 20.35 during off periods and 13.65 during on periods. Mean Schwab and England Scale was 47 off period and 56.5 during on period.

Table 1: Patient demographics and percentage of thalamotomy and pallidotomy procedures for patients with Parkinson's disease (No. $=10$ )

\begin{tabular}{lll}
\hline Age & Mean \pm SD & $50.5 \pm 16.35$ \\
& Range & $17-70$ years \\
Sex & Female & $4(40 \%)$ \\
& Male & $6(60 \%)$ \\
Duration of PD & Mean \pm SD & $8 \pm 3.1$ \\
& Range & $2-12$ years \\
Main side affected & Right & $6(60 \%)$ \\
& Left & $4(40 \%)$ \\
Tremor predominant & & $5(50 \%)$ \\
Rigidity predominant & & $2(20 \%)$ \\
Combined tremors and rigidity & $3(30 \%)$ \\
Bilateral procedures (= simultaneous, staged, and & $3(30 \%)$ \\
crossed) & & \\
Thalamotomy group & & $5(50 \%)$ \\
Pallidotomy group & $2(20 \%)$ \\
Combined group & $3(30 \%)$ \\
\hline
\end{tabular}

Motor subscores are calculated by the following method (from UPDRS):tremors: Questions no. 16, 20 , and 21. Rigidity: 22 and 28. Bradykinesia: 23-27, 29, and 31 .

Patients were divided into three groups according to their presentation and the operation done for them

- $\quad$ Thalamotomy group: Presented with tremorpredominant PD and was operated upon by thalamotomy

- Pallidotomy group: Presented with rigid a kinetic-predominant PD and was operated upon by pallidotomy

- $\quad$ Combined group: Presented with combined symptoms and was operated upon by combined thalamotomy and pallidotomy.

\section{Thalamotomy group}

Five patients were included in this group who presented with tremor-predominant IPD. They were operated on by Vim thalamotomy. Patients were informed 
preoperatively that other Parkinsonian symptoms will not improve with a satisfactory percentage keeping in mind that tremors are their only or significant complaint.

Preoperatively, the UPDRS III off and on, respectively, was 24.4/15.2 and postoperatively was $13 / 7.4$ with improvement $47 \% / 51 \%$. The tremor subscore was 5.4/2.8 preoperatively and 1.4/0.8 postoperatively with average of $72 \%$ improvement. The UPDRS II pre was 17.2/11.6 and post it became 10.6/7 with $39 \%$ improvement modified $\mathrm{H}$ and $\mathrm{Y} 2.4 / 1.7$ pre and post-operatively (29\% improvement).

\section{Pallidotomy group}

Two patients were included in this group who presented with rigid a kinetic-predominant IPD. They were operated upon by GPi pallidotomy. Patients were informed preoperatively that tremors symptom will not improve with a satisfactory percentage keeping in mind that rigidity, bradykinesia, and dyskinesia are their main significant complaint.

Preoperatively, the UPDRS III off and on respectively was $38.5 / 23.5$ and postoperatively was $28 / 16$ with improvement $27 \% / 32 \%$. The rigidity subscore was $5 / 2.5$ preoperatively and $2 / 1$ post-operatively with average of $60 \%$ improvement. The bradykinesia subscore was 9/5.5 pre-operatively and 5.5/2.5 postoperatively with average of $47 \%$ improvement. The dyskinesia subscore was 4.5 preoperatively and 1.2 postoperatively with average of $71 \%$ improvement. The UPDRS II pre was 22/12.5 and post it became 16/10 with $25 \%$ improvement modified $\mathrm{H}$ and $\mathrm{Y} 2.75 / 2.25$ pre and post-operatively (18\% improvement).

\section{Combined group}

Three patients were included in this group who presented with combined symptoms of IPD. They were operated on by combined thalamotomy and pallidotomy.

Preoperatively, the UPDRS III off and on, respectively, was 41.33/28.67 and postoperatively was $15.67 / 11.33$ with improvement $62 \% / 60 \%$. The rigidity subscore was $5 / 3.33$ preoperatively and $1.67 / 1$ postoperatively with average of $68 \%$ improvement. The bradykinesia subscore was $10 / 6$ preoperatively and 4/1.33 postoperatively with average of $72 \%$ improvement. The UPDRS II pre was $28.33 / 19.33$ and post it became 16.33/10.67 with $43 \%$ improvement modified $\mathrm{H}$ and $\mathrm{Y} 2.83 / 2$ pre and post-operatively $(29 \%$ improvement).

\section{Complications (Table 2)}

Regarding complications, we did not encounter any intra-operative complications neither mortality. Changing the initial target coordinates obtained from images after functional localization of the desired nucleus is not considered a surgical error and is part of our functional localization of the target. Post-operative, two patients (20\%) of the thalamotomy group developed gait disturbance in the form of mild ataxia towards the side of tremor relief, these patients on neurological examination had no actual weakness. Moreover, both of them improved after 2 weeks of surgery and returned to normal. Two patients (20\%) who received bilateral staged combined pallidotomy and thalamotomy developed speech abnormality in the form of slight dysarthria that improved after few days of surgery. Another patient (10\%) from thalamotomy group complained of memory deficit in his first follow-up visit, his MMSE score was nearly the same as the pre-operative score, we have added some medications and he didn't complain about it again. A patient $(10 \%)$ who underwent thalamotomy complained of contralateral oral hypoesthesia that improved after few weeks of surgery. This was observed during the temporary lesion step that made us change the target coordinates accordingly to a more anterior target.

Table 2: Complications and their percentage

\begin{tabular}{lll}
\hline Complication & No. (\%) & Type of procedure \\
\hline Transient gait disturbance & $2(20 \%)$ & Thalamotomy (2) \\
Transient speech affection & $2(20 \%)$ & Bilateral GPi \& Vim (2) \\
Memory deficit & $1(10 \%)$ & Thalamotomy (1) \\
Hypoesthesia contralateral to lesion & $1(10 \%)$ & Thalamotomy (1) \\
\hline
\end{tabular}

\section{Statistical analysis of the data}

Concerning previous table there is high significant statistical finding in all clinical score and subscore of Parkinsonian symptoms with percentage decrease of symptoms ranging from $23.4 \%$ in modified $\mathrm{H}$ and $\mathrm{Y}$ to $75.47 \%$ in controlling tremors postoperative during off period (Table 3 , Figures 7, 8-13, for details).

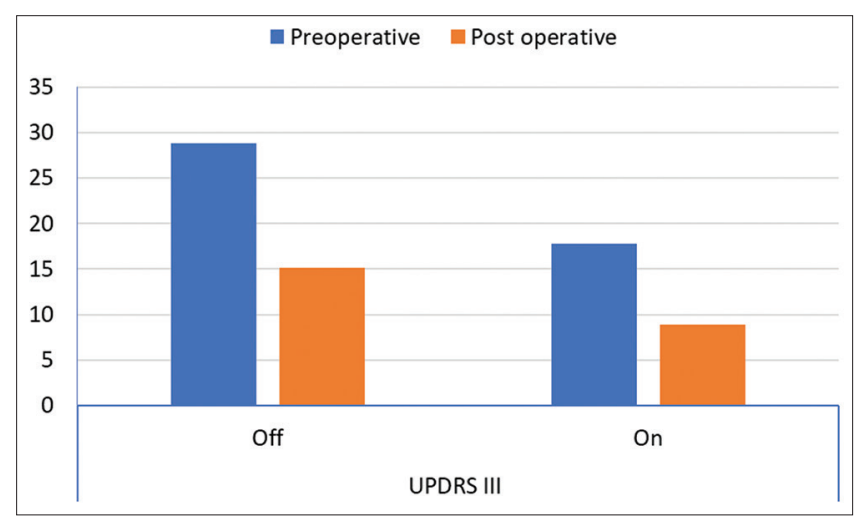

Figure 8: Chart of Unified PD Rating Scale III on/off before and after surgeries showing $48.6 \%$ reduction of score post-operative during On/Off periods

\section{Case presentation}

M.A.M a 70-year-old male patient presented with IPD for 10 years. The disease started by Rt upper 
limb rest tremors that progressed to involve Rt lower limb with a year interval between both. The condition then progressed to involve the whole body.

Patient started Antiparkinsonian medications 10 years ago, the condition improved at that time with medical treatment, but after 4 years the patient needed to increase the dosage of medications and to change the medications themselves.

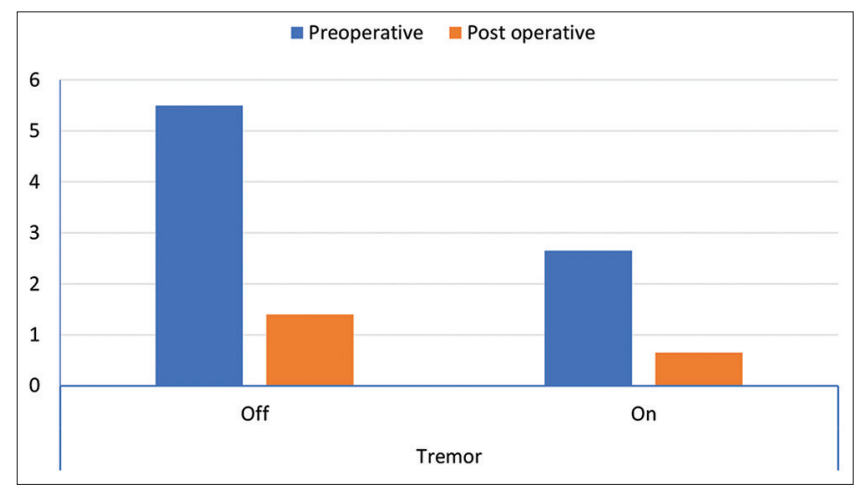

Figure 9: Tremor subscore showing mean reduction of $75 \%$ in relation to pre-operative scores

Three years before admission, the tremors started to become resistant to medications and the patient sought medical advice where he tried different medications and different combinations which all failed to improve the tremors. This rendered the pt. unable to resume his social activities and caused social embarrassment that made him to prefer not to get out his home.

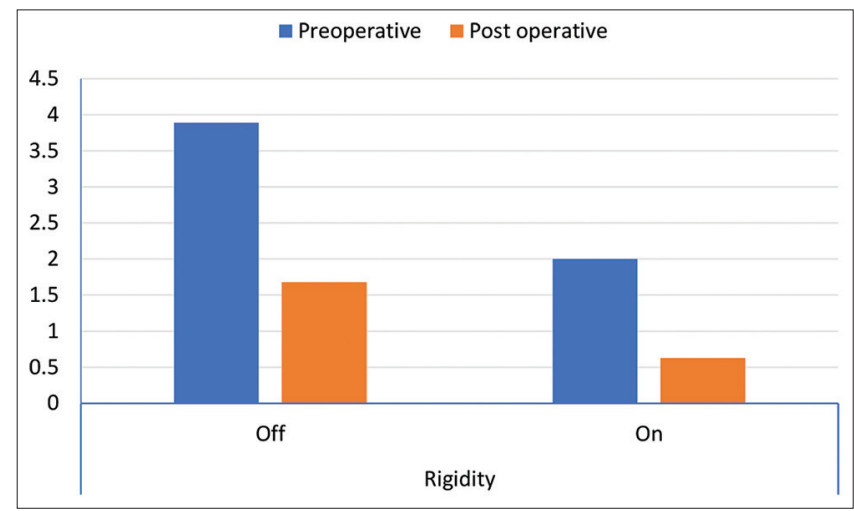

Figure 10: Rigidity subscore showing mean reduction of $62.6 \%$

The pt. complains of bradykinesia but he records good improvement after medications.

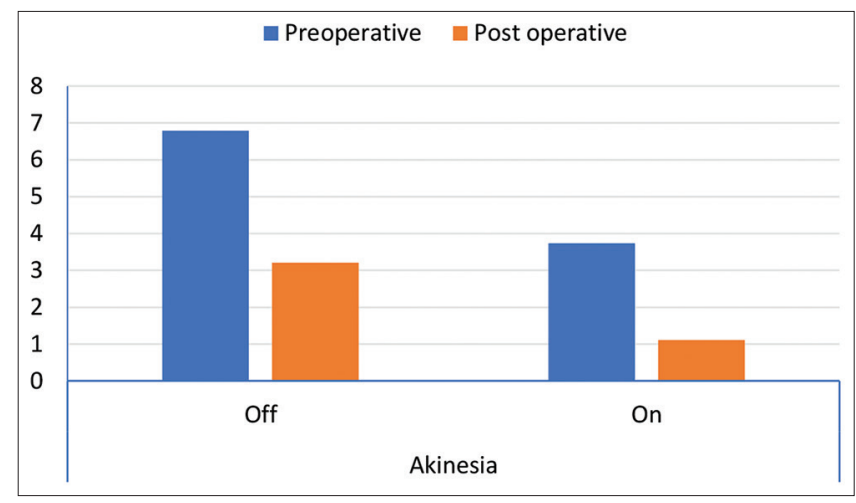

Figure 11: Bradykinesia subscore showing mean reduction of $61.5 \%$ in relation to pre-operative scores

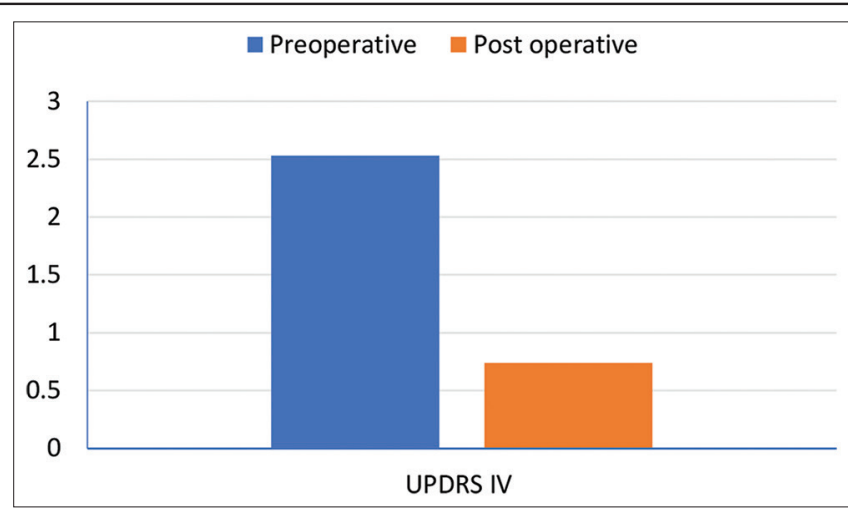

Figure 12: Unified PD Rating Scale IV score (drug motor complications) showing mean reduction of $70.73 \%$

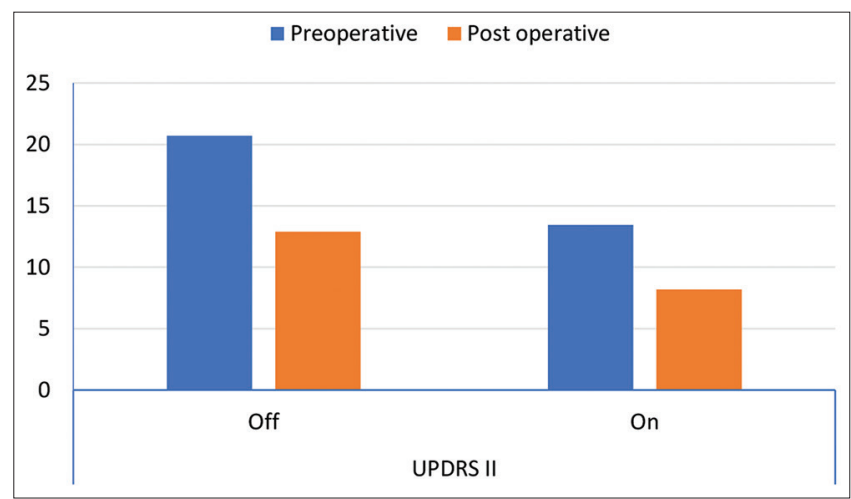

Figure 13: Unified PD Rating Scale II score showing mean reduction of $38.3 \%$ in on/off state

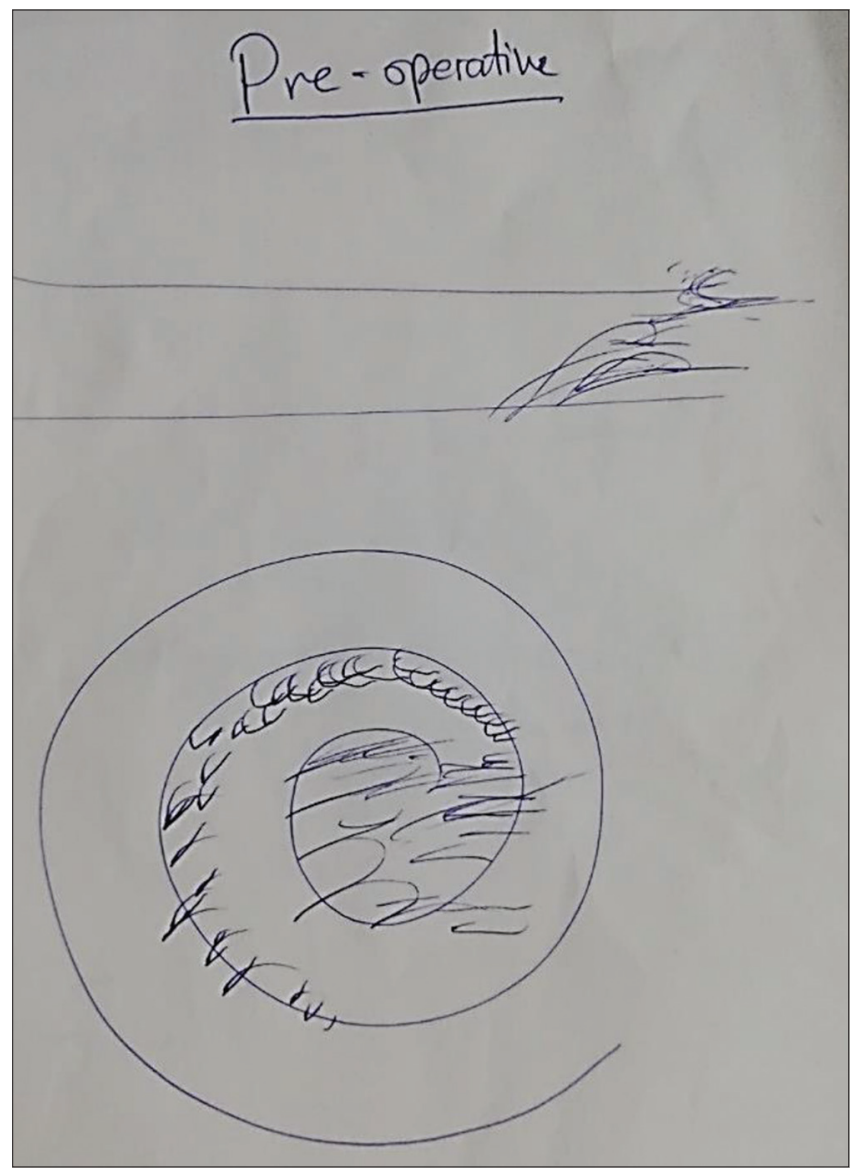

Figure 14: Pre-operative trial of patient to write his name (above) and to draw a swirl (below). Note that the uninterrupted line is the physician's handwriting 
Table 3: Statistical results of assessment score pre-operative and 6 months post-operative with correlating significance value

\begin{tabular}{|c|c|c|c|c|c|c|c|c|}
\hline \multirow[t]{2}{*}{ Blank Cell } & \multicolumn{2}{|c|}{ Pre-operative } & \multicolumn{2}{|c|}{6 months post-operative } & \multirow{2}{*}{$\begin{array}{l}\% \text { of } \\
\text { improvement }\end{array}$} & \multirow[t]{2}{*}{ Test } & \multirow[t]{2}{*}{$p$ value } & \multirow[t]{2}{*}{ Sig. } \\
\hline & Mean & SD & Mean & $\mathrm{SD}$ & & & & \\
\hline \multicolumn{9}{|l|}{ UPDRS III } \\
\hline \multicolumn{9}{|l|}{ Q. 18-31 } \\
\hline \multicolumn{9}{|l|}{ Maximum=56 } \\
\hline Off & 28.80 & 14.23 & 15.15 & 6.82 & 47.40 & 5.495 & $<0.001$ & HS \\
\hline On & 17.75 & 10.98 & 8.90 & 5.15 & 49.86 & 5.323 & $<0.001$ & HS \\
\hline \multicolumn{9}{|l|}{ Tremor } \\
\hline \multicolumn{9}{|c|}{ Q. 16,20 and 21} \\
\hline \multicolumn{9}{|l|}{ Maximum=12 } \\
\hline Off & 5.50 & 3.41 & 1.40 & 1.31 & 74.55 & 8.252 & $<0.001$ & HS \\
\hline On & 2.65 & 2.06 & 0.65 & 1.09 & 75.47 & 6.686 & $<0.001$ & HS \\
\hline \multicolumn{9}{|l|}{ Rigidity } \\
\hline \multicolumn{9}{|l|}{ Q. 22 and 28} \\
\hline \multicolumn{9}{|l|}{ Maximum=8 } \\
\hline Off & 3.89 & 2.00 & 1.68 & 1.16 & 56.83 & 7.099 & $<0.001$ & HS \\
\hline On & 2.00 & 1.49 & 0.63 & 0.68 & 68.42 & 5.600 & $<0.001$ & HS \\
\hline \multicolumn{9}{|l|}{ Bradykinesia } \\
\hline \multicolumn{9}{|c|}{ Q. $23-27,29$ and 31} \\
\hline \multicolumn{9}{|c|}{ Maximum $=28$} \\
\hline Off & 6.79 & 3.88 & 3.21 & 1.93 & 52.71 & 5.791 & $<0.001$ & HS \\
\hline On & 3.74 & 2.94 & 1.11 & 1.10 & 70.36 & 4.718 & $<0.001$ & HS \\
\hline UPDRS IV & 2.53 & 3.88 & 0.74 & 1.19 & 70.73 & 2.868 & 0.010 & $\mathrm{~s}$ \\
\hline \multirow{2}{*}{\multicolumn{9}{|c|}{$\begin{array}{l}\text { Q. } 32-42 \\
\text { UPDRS II }\end{array}$}} \\
\hline & & & & & & & & \\
\hline \multicolumn{9}{|l|}{ Q. $5-18$} \\
\hline \multicolumn{9}{|l|}{ Maximum=52 } \\
\hline Off & 20.70 & 8.51 & 12.90 & 5.00 & 37.68 & 7.111 & $<0.001$ & HS \\
\hline On & 13.45 & 5.79 & 8.20 & 3.61 & 39.03 & 6.811 & $<0.001$ & HS \\
\hline \multicolumn{9}{|c|}{ Schwab and England } \\
\hline Off & 47.00 & 14.90 & 63.00 & 12.18 & 34.04 & -6.532 & $<0.001$ & HS \\
\hline On & 56.50 & 14.96 & 82.00 & 8.94 & 45.13 & -12.074 & $<0.001$ & HS \\
\hline Modified H\&Y & 2.68 & 0.373 & 2.05 & 0.394 & 23.4 & 2.093 & $<0.001$ & HS \\
\hline
\end{tabular}

The patient does not complain of gait or postural instability nor rigidity.

By examination: The pt. had severe rest tremors, postural tremors and mild kinetic tremors. No ataxia or cerebellar signs (Figure 14).

The patient had MRI brain and no structural pathology was identified. The patient was planned for Lt Vim thalamotomy to improve the Rt sided tremors.

Intraoperatively, the operation went smooth without any side effects or undesired effects. We performed three lesions after final anatomical (stereotactic) and physiological (functional) localization of the nucleus each one is $75^{\circ} \mathrm{C}$ for $80 \mathrm{~s}$.

Postoperatively, the Rt sided tremors resolved completely. No effect on other Parkinsonian symptoms. No reduction in levodopa medications (Figure 15).

\section{Discussion}

The known loss of dopaminergic cells in the pars-compacta of the substantia nigra that is the hallmark of PD. The cellular pathophysiology of the motor dysfunction is beginning to be better understood, thereby providing a stronger scientific rationale for surgical interventions. Yet, to date, there are no treatments that prevent, halt, or cure PD. Surgical strategies, offer symptomatic relief or control of motor complications associated with drug treatment.

Both pallidotomy and thalamotomy were extensively used in the treatment of PD in the1950's and 1960's. With the introduction of levodopa (L-dopa)

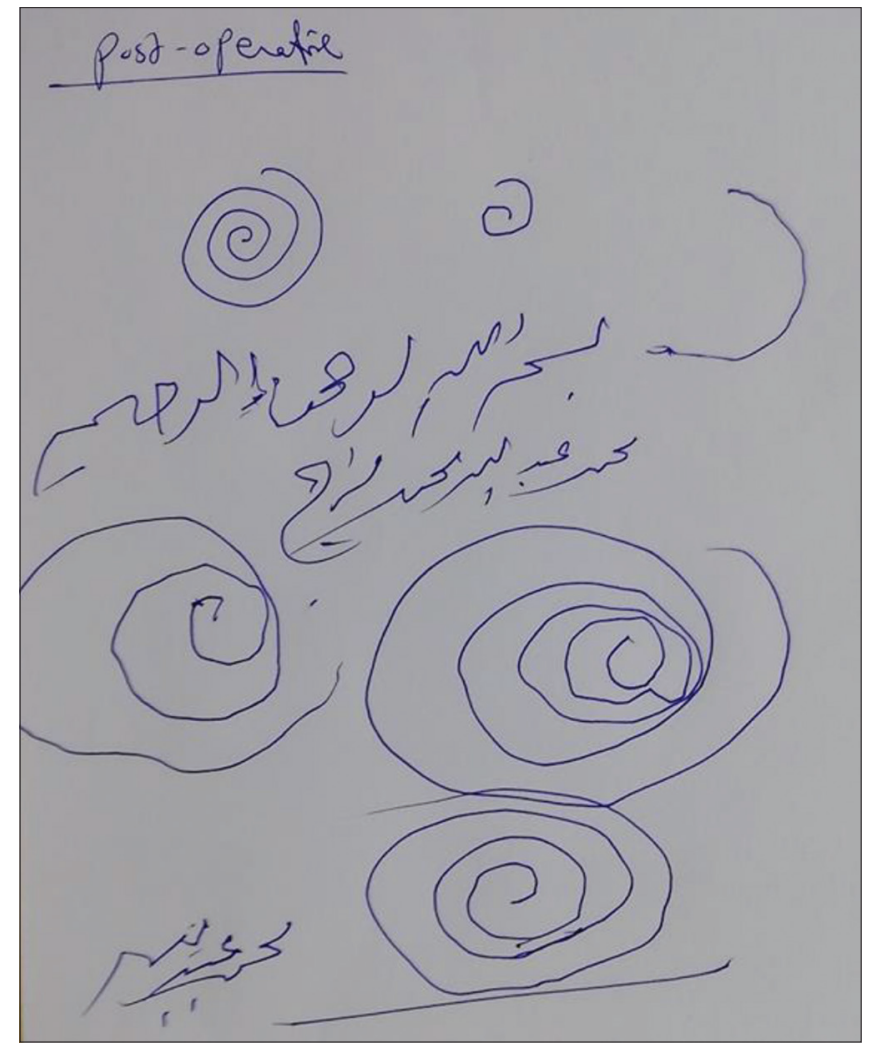

Figure 15: Immediate post-operative trial of pt to write his name and draw swirls

in the1960's and the realization of its striking benefits, surgery was almost abandoned and used only for patients with severe tremor. Surgical therapy is now being used earlier and more often due to several factors:

Medications have shortcomings, and many patients continue to be disabled despite the best available drug therapy. 
Technical improvements in brain imaging, in neurosurgical techniques and devices, and in intraoperative electrophysiology have made procedures safer and more accurate.

With the rediscovery of functional neurosurgical procedures for the treatment of $P D$, there have been a large number of reports testing a variety of surgical approaches to treat PD. These surgical procedures are complex. Due to the novelty of these surgical approaches, this study documenting their efficacy and safety.

There are currently three brain regions being considered as targets for functional neurosurgery for PD (other than transplantation). Either central nervous system lesions (thalamotomy, pallidotomy or STN lesions) or implants of chronic stimulating electrodes at these sites (DBS) are being used.

These targets are: The VIM nucleus of the thalamus $(\mathrm{Vim})$, the internal segment of the $\mathrm{GPi}$, and the STN.

In general, the Vim target is used to treat tremors with minimal or no effect on other Parkinsonian symptoms as rigidity and bradykinesia. On the other hand, the pallidal and subthalamic targets are used to treat akinesia, rigidity, gait and postural disturbances, and drug induced dyskinesias, but with less improvement of tremors in pallidal targets and risk of dyskinesias or hemiballismus in subthalamic targets especially in lesioning rather than stimulation. The common surgical practice prefers bilateral simultaneous stimulation procedures rather than bilateral simultaneous ablation. Given the advances in surgical expertise and in understanding the neurodegenerative changes associated with PD, clinical reports are published in the literature reporting on safety and efficacy of these procedures.

\section{Demographic data}

In our study, we operated upon 10 IPD patients who were meeting our selection criteria by ablative procedures contralateral to Parkinsonian symptoms, age of the patients ranged $17-70$ year with mean of 50.5 \pm 16.35 years with predominance in males representing 6 patients. Mean duration of PD according to history ranged from 2 to 12 years with mean of $8 \pm 3.1$ years. The disease was mainly bilateral asymmetrical with the right side being the more affected and the procedure done was more common on the left side. These demographic data are consistent with previous studies done in that field [7].

\section{Target choice}

We performed Thalamotomy alone for tremor predominance Parkinson's with minimal rigidity of bradykinesia, and pallidotomy alone for L-dopa dyskinesia, bradykinesias or rigidity predominant types of PD. We performed combined contralateral pallidotomy and thalamotomy in patients with combined symptoms giving more than $30 \%$ improvement in UPDRS III after L-Dopa testing.

Fayed et al. in 24 patients with tremor predominant PD performed unilateral PVP in 12 patients and compared them to 12 patients had combined PVP and VIM Thalamotomy, he concluded that the addition of Vim lesion gives better outcome on tremor subscore promoting patient satisfaction and improving overall quality of life postoperatively [7].

Some authors advocate for the use of pallidotomy as the preferred target claiming that a well-placed lesion in the pallidum is equally effective to thalamic lesions in the treatment of Parkinsonian tremor, even for tremor predominant patients but this finding was not consistent throughout the literature [8] and also in our experience as in the patients with pallidotomy, though not tremor dominant in our patients, the improvement of tremors was often partial or late.

\section{Assessment of the patients}

Patients with PD almost care for treating specific symptoms, tremors, bradykinesia, and rigidity come in their highest priority than other UPDRS III motor features.

UPDRS assessment of the patients are done in both on and Off periods, mean UPDRS III for motor symptoms was 28.8 and 17.75 for Off/On, respectively. However, from our experience performing this study, we have found that UPDRS III reflects the real patient condition and expectation. However, the most important subscores in UPDRS III to be assessed separately are tremor, bradykinesias, rigidity subcores, and L-Dopa equivalent daily dose. These subscores were used in many other studies [9].

In our study, mean tremor subscore was 5.5/2.65 for Off/On preoperative. Mean rigidity subscore was $3.89 / 2$, Bradykinesia subscore was 6.9/3.74, note that for patient selection it is recommended that there is difference $>30 \%$ improvement on UPDRS III between On/Off conditions. These selection criteria came in consistent with almost all previous studies [10], [11]. Our study reported mean UPDRS II score for daily life habits was 20.7 during off periods and 13.45 during on periods. Mean Shwab and England Scale was 47 off period and 56.5 during on period.

\section{Surgical technique}

Our technique is considered one of the updated techniques used in recent literature relying on performing preoperative high-resolution MRI, applying the stereotactic frame and performing high resolution CT scan with fiducials, then we fuse both images to detect AC-PC plane, the we put the preset target coordinates 
of VIM or GPI and perform minor adjustments according to the location of the target. In reviewing the literature, image fusion using CT fiducials is considered more accurate than MRI fiducials due to minor shift of the image formed by MRI leading to vector error of target location from $0.5 \mathrm{~mm}$ to $1.5 \mathrm{~mm}$ [12].

After target calculation and introducing brain electrode, we rely on micro thalamotomy effect as a good sign of good localization, after that we perform motor and sensory stimulation at 2 and $50 \mathrm{~Hz}$ respectively, we avoid getting capsular or sensory stimulation below 2 or $1 \mathrm{mV}$ respectively, finally we perform lesioning using gradual rise of temperature starting from 45 degrees for $30 \mathrm{~s}$ as a functional testing to avoid capsular damage then we gradually rise the temperature up to 75 degrees for $60 \mathrm{~s}$. This surgical technique is the same as those mentioned in many previous studies [7], [13].

\section{Use of MER}

In our study, we did not use MER in any of our patients. We use the anatomical target localization as an initial step for target identification. However, we used macrostimulation and impedance measurement as a form of physiological verification of these targets as a necessary step before the final target could be confirmed.

We think that macrostimulation beside being easy and quick and requiring minimal instrumentation, can identify a wide range of structures even at distance from the probe and thus gives the surgeon a clue where to move next. Unlike MER where the tip of the electrode has to be very close to the structure before it can be detected. Furthermore, The GPi are relatively larger nuclei, than, for example, the STN, so precision of placement of the lesion can be relatively less yet still offer optimum clinical results with minimal collateral damage. Last but not least; the higher cost of MER equipment with no evidence of added benefit makes its routine use in procedures like pallidotomy not a feasible option in a developing country like Egypt in which this study was carried out. Our macrostimulation and modification of target dependent on, it might be the cause of the absence of any visual affection in our series; on the other hand, clinical improvement was equivalent. Hemorrhagic complications are mentioned more with the use of MER. However, MER is more helpful in identifying the optic tract in pallidal operations.

Our results demonstrate that pallidotomy performed without microelectrode guidance can provide the desired effect without added morbidity or risk. This is consistent with the findings of Israel et al. [14] and Palur et al. [15].

\section{Pallidotomy}

In our patients, we use posteroventralpallidotomy $(\mathrm{PVP})$ to patients who complain mainly of rigidity, bradykinesia, and/or Levodopa induced dyskinesia.

Of all results related to pallidotomy, the most consistent and clinically significant contribution has been the control of dyskinesias, especially contralateral to the side of the lesion. Kondziolka et al. found contralateral dyskinesia dropped from mean scores of $1.5-0.9$ by 9 months with persistence of effects at 18 months in the 21 patients followed for that duration [16]. In Giller's report using a 0-3 severity rating system (for each side), they found dyskinesia dropped from a mean 5.5 preoperatively to 2.1 at 2 weeks and remained improved [17]. The scores were even more dramatic when only the contralateral dyskinesia ratings were considered (2.5-0.2). Shannon found similar improvements using the UPDRS-based dyskinesia ratings, finding significant improvements in both duration score (mean baseline 2.2 vs. 1.0 at 6 months) and severity score (mean 1.5 vs. 0.5) [18]. Baron had reported the results of a 1-year pilot study regarding the effects of unilateral GPi pallidotomy in 15 advanced PD patients. The mean total UPDRS score improved by $30 \%$, mean ADL "off" subscale scores improved by $34 \%$ and the motor examination "off" score improved by $25 \%$. There was a dramatic improvement in contralateral drug-induced dyskinesias and tremor [19].

There is statistically high significant clinical response in rigidity, bradykinesia and L-Dopa induced dyskinesias of $62.6 \%, 61.5 \%$, and $71 \%$, respectively, in review of previous studies, Lozano [20], in 14 patients with 7 months follow-up reported $100 \%$ improvement of L-Dopa induced dyskinesias, 35\% improvement of rigidity and bradykinesia after unilateral pallidotomy, in his study he excluded patients with severe tremors, and that what Fayed et al. developed in 2018 [7] to perform combined pallidotomy and Thalamotomy to manage patients with disabling tremors combined with bradykinesia and rigidity. Lozano also reported less improvement on midline symptoms as postural instability and gait disorder; he reported also mild improvement of the ipsilateral side [20].

There are two randomized control studies comparing pallidotomy to best medical treatment advanced Parkinsonian patients with their result illustrating the superiority of pallidotomy against best medical treatment alone which this study results came in consistent with [21], [22].

\section{Thalamotomy}

The thalamic nuclei have been the target of studies related to stereotaxic surgery for several decades. Whereas the nucleus ventralis intermedius (Vim) is the primary target, the nucleus ventralis lateralis, including ventro-oral-thalamic (Voa and Vop) as well as the reticular thalamic nucleus have also been studied. In our series patients, we used VIM thalamotomy for tremor dominant PD patients. 
Jankovic et al. evaluated 43 PD patients undergoing stereotaxic thalamotomy of the ventralis intermedius nucleus using a global tremor rating and the tremor score from the UPDRS. L-dopa doses were also monitored. Thirty-nine patients had one lesion and three had repeated operations on the same side. Two had bilateral surgery. All these operations were considered together for the analysis of patient outcome. In $72 \%$, abolition of tremor occurred and $14 \%$ showed significant improvement [23].

Our results demonstrate that thalamotomies performed can provide a marked and rapid improvement in contralateral tremor in almost all the patients, but the reduction in the UPDRS scores was more marked in the pallidotomy group than the thalamotomy group. Our results are correlated to the results of all studies of thalamotomy which have been performed in patients with tremor insufficiently controlled by oral medications and was shown that there is INSUFFICIENT EVIDENCE to conclude on the efficacy of thalamotomy in the symptomatic control of other Parkinsonian symptoms like bradykinesia, rigidity, and the tremor ipsilateral to the surgery.

\section{Lesioning versus DBS}

Schuurman et al. compared the efficacy of thalamotomy and thalamic DBS for treatment of drugresistant tremor in 45 patients with $\mathrm{PD}$. Patients were randomized to treatment, and the primary outcome measure was the change in functional abilities measured by Frenchay Activities Index scores 6 months after surgery. As a secondary outcome, they measured the tremor score from the UPDRS motor section. In both groups, the target nucleus was the nucleus ventralis intermedius (Vim). Functional status improved in both groups and was significantly greater in stimulation group. On the Frenchay scale, the mean score changed from 32.0 to 32.5 in the thalamotomy group and from 31.4 to 36.3 in the stimulator group. The difference between groups for change scores was 4.7 in favor of DBS. Tremor was more improved with stimulation as well, but the differences between this treatment and thalamotomy was not statistically significant. Electrical stimulation was favored additionally because of safety issues with 11 patients having persistent adverse effects at six months after surgery in the thalamotomy group compared to only two in the stimulation group. Among the persisting effects in the thalamotomy subjects, cognitive deterioration, dysarthria, hyperasthesia, gait and balance disturbance, and arm ataxia occurred. In the stimulator group, dysarthria was the only persisting effect and in both cases was considered mild. One patient in the stimulation group, however, died perioperatively after a cerebral hemorrhage [24].

This observation was not reached in our study as the DBS procedure is of a high cost that exceeded our affordability. However, by reviewing other cases from database of other surgeons, we could reach the same conclusion that both procedures have the same efficacy [8].

\section{Complications}

Considering complications, we did not encounter any permanent deficits, a value comparable to previous studies in which permanent deficits ranged from $1 \%$ to $6 \%$ [25] all with good outcome. In this respect, our results are also similar to previous studies [26] Transient gait disturbance and speech abnormalities are mentioned in both pallidotomy and thalamotomy. However, we have found that thalamotomy has a higher risk as the Vim is surrounded by fibers related to motor and cerebellar functions compared to the GPi. Memory loss was found to be around $1.5 \%$ - $6 \%$ in some studies [27]. Although we did not have any intracerebral hemorrhages, there was a higher risk of hemorrhage when the VIM was targeted than when GPi was targeted reported by Terao and Ben Haim [28], [29].

Adverse reactions are common with pallidotomy. The majority is minor and well tolerated, but there is a risk of serious adverse reactions including of intracerebral hemorrhage (common to all stereotactic operations), speech impairment, especially with bilateral surgery, and visual adverse reactions in the form of field defects. Field defects are so common with pallidotomy up to $20 \%$ in some publications. We believe that our group of patients was not that aware of identifying visual stimulation during optic stimulation, small sample size and their level of education were contributing factors for no visual side effects in our series. Moreover, we used to go 1-2 $\mathrm{mm}$ up the normal pallidal target which is $\mathbf{4 - 5} \mathbf{m m}$ inferior to the AC-PC line.

Mortality in movement disorder surgery has been frequently reported. The mortality rate was found to be $1.2 \%$ in a systematic review including 12 prospective studies with 334 pallidotomy patients [30]. The most common causes of which are intracerebral hematoma along the trajectory or, less, at the target site, other causes included pulmonary embolism, aspiration pneumonia but we have no mortality in our series.

\section{Bilateral procedures}

Considering bilateral procedures, we reported three patients two of them had staged bilateral pallidotomy and thalamotomy, and the third had staged bilateral pallidotomy. We reported significant improvement of $55 \%$ of UPDRS III without significant complications, these results came in consistent with Favre who reported 17 patients with bilateral simultaneous PVP with $76 \%$ of overall UPDRS III score at 7 months follow-up with a preference to younger age (<60 year) with no or minimal effect of speech deterioration. 
Furthermore, we noticed that there is no effect of lesioning surgeries even with bilateral lesions on cognitive function (we reported three cases in this study) these data are consistent with many studies done in the past two decades rather than the older studies which reported many cognitive and speech complications of bilateral lesions maybe due to modern targeting techniques and development of high precise radiofrequency machines giving controlled thermal lesion to the target, Chung et al. reporting eight patients reported simultaneous bilateral PVP may be a safe and highly effective method of reducing levodopa-induced dyskinesia for advanced PD with severe levodopa-induced dyskinesia [31].

Considering long term follow up, York et al. in 15 patients with 2-year retrospective analysis after staged bilateral PVP showed bilateral pallidotomy patients tended to show an increase in both motor and non-motor symptoms of PD, particularly cognitive decline [32]. In contrary, Morello in 2001 compared three patients with bilateral PVP vs. unilateral pallidotomy and simultaneous contralateral pallidal stimulation, he found that all three patients developed cognitive dysfunction, increased freezing and gait disturbance that led him to stop the sample and perform combined PVP and pallidal stimulation [33]. We have found he used MER in his study and lesioning parameters of 75 degree for $60 \mathrm{~s}$ that looks similar to our protocol, but did not mention the diameter of the electrode used or the use of macrostimulation or the target coordinates he used in his study, probably improper lesion site can lead to the aforementioned complication.

However, we have noticed that long term follow-up of DBS in 103 patients [34] showed cognitive decline in $20-40 \%$ after 2 years of surgery that let us confounding between the natural history of disease and stereotactic surgeries at all.

Our results confirm the efficacy of stereotactic surgeries at 6 months follow-up after surgery, with marked reductions in PD symptoms, dyskinesia intensity, and required doses of dopaminergic medication. Our results are in good overall agreement with previous studies. Previous studies have reported efficacy values ranging from $30 \%$ to $74 \%$ [35]. Furthermore, an exhaustive review of the literature [36] concluded that many studies either reported a percentage improvement without giving full data, or only reported cases with specific complications. Our study reports all treatment results for all consecutively included patients with L-dopa sensitivity higher than $30 \%$.

The improvement in axial signs was less significant than for the limbs and was comparable to the values (ranging from $43 \%$ to $55 \%$ ) published in other studies reporting an improvement in gait and postural stability, to the best of our knowledge [37]. Moreover, we observed a synergistic effect of pallidotomy and L-dopa, which was significant for both axial and limb symptoms. The $35.1 \%$ improvement in the UPDRS Part II score, which assess activities of daily living, was also consistent to the results from other studies, which range from $30 \%$ to $70 \%$ [38].

Considering complications of L-Dopa medications, the $70 \%$ improvement in the UPDRS Part IV A score in our study was also comparable to literature values, which range from $55 \%$ to $92 \%$ [39].

\section{Financial burden}

We would like to emphasize that till the finishing of this study DBS was not supported financially by the governmental sector of health insurance. Stereotactic lesioning procedures do not have extra costs in the operation room except for the RF lesion generator, stereotactic frame (which are found normally in most neurosurgical departments of specialized centers) and the RF electrode which costs around 5000 Egyptian pounds ( $\approx 319$ USD). The patient is discharged next day of operation and thus no extra burden for the patient's accommodation or medications.

DBS patients have a great financial burden in our country; the active PC battery costs around 650,000 Egyptian pounds ( $\approx 41519$ USD). The patient is accommodated for 1 week as an average postoperatively with accommodation and medications expenses.

\section{Study limitations}

This study had several limitations. It was not compared with a control population or with a group of different modalities of management and consequently a placebo effect or natural improvement could not be assessed. In addition, due to financial issues, we couldn't perform DBS surgeries to assess the outcome or use MER for VIM or GPi localization; hence, we relied on macrostimulation guidance and somatotopic maps for localization.

The relatively small sample size with the short follow-up period may not give a solid evidence on the long-term efficacy of the treatment modalities we used in this study. Hence, we need to conduct further studies considering large sample size and longer follow-up duration.

The COVID-19 pandemic that stroke the world and affected Egypt by the beginning of 2020 caused a year of delay in our study due to the lockdown precautions and the quarantine policy of our hospital which postponed all elective procedures for chronic patients with non-emergency diseases (e.g., Parkinsonian patients).

Exploring new targets such as the STN and the PPN in the field of ablative surgery or DBS surgeries would be of a great value. This needs great experience in the field of stereotactic neurosurgery. 


\section{Conclusion}

The study concludes that lesioning procedure should be revisited globally using the modern techniques of targeting and controlled thermal lesion protocols guided by capsular somatotopy and intraoperative macroelectrode stimulation that will improve the outcome dramatically.

The study recommends surgery for patients with PD as soon as possible in case of refractory tremors, and we can wait for patients with rigidity and bradykinesia to 5 years until side effects of L-Dopa medications appear. The exact timing of surgery should be tailored according to each patient presentation and disease burden on his lifestyle.

Functional neurosurgery procedures and implanted devices have a huge cost burden on both the government and the patients in our country, but we should not abandon these interventions as they have a great effect on patients' quality of life. Lesioning procedure looks to be the best available option for the developing countries and countries without solid insurance system.

The data considering the unwanted effects of bilateral lesioning such as cognitive dysfunction or speech deterioration needs more studiesto prove it.

\section{References}

1. Lozano AM. In: Lozano AM, Gildenberg PL, Tasker RR, editors. Textbook of Stereotactic and Functional Neurosurgery. Berlin, Heidelberg: Springer; 2009. https://doi. org/10.1007/978-3-540-69960-6

2. DeLong MR, Wichmann T. Basal ganglia circuits as targets for neuromodulation in Parkinson disease. JAMA Neurol. 2015;72(11):1354-60. https://doi.org/10.1001/ jamaneurol.2015.2397

PMid:26409114

3. Winn HR. Youmans and Winn Neurological Surgery. $7^{\text {th }}$ ed. Amsterdam, Netherlands: Elsevier; 2017.

4. Alkire BC, Raykar NP, Shrime MG, Weiser TG, Bickler SW, Rose JA, et al. Global access to surgical care: A modelling study. Lancet Glob Health. 2015;3(6):e316-23. https://doi.org/10.1016/ s2214-109x(15)70115-4

PMid:25926087

5. Fezeu F, Ramesh A, Melmer PD, Moosa S, Larson PS, Henderson F. Challenges and solutions for functional neurosurgery in developing countries. Cureus. 2018;10(9):e3314. https://doi.org/10.7759/cureus.3314 PMid:30473947

6. Lozano AM, editor. Progress in neurological surgery. In: Movement Disorder Surgery. Vol. 15. Basel, Switzerland: Karger AG; 2000. p. 188-95.

7. Fayed ZY, Radwan H, Aziz M, Eid M, Mansour AH, Nosseir M, et al. Combined unilateral posteroventral pallidotomy and ventral intermediate nucleus thalamotomy in tremor-dominant parkinson's disease versus posteroventral pallidotomy alone: A prospective comparative study. Stereotact Funct Neurosurg. 2018;96(4):264-9. https://doi.org/10.1159/000492229 PMid:30227440

8. Eid M. Surgical Management of Parkinson's Disease. Egypt: Ain Shams University; 2018.

9. Xu C, Zhuang P, Hallett M, Zhang Y, Li J, Li Y. Parkinson's disease motor subtypes show different responses to longterm subthalamic nucleus stimulation. Front Hum Neurosci. 2018;12:365. https://doi.org/10.3389/fnhum.2018.00365 PMid:30337863

10. Charles D, Konrad PE, Davis TL, Neimat JS, Hacker ML, Finder SG. Deep Brain Stimulation in Early Stage Parkinson's Disease. Parkinsonism Relat Disord. 2015;21(3):347-8. https:// doi.org/10.1016/j.parkreldis.2014.10.032

PMid:25547949

11. Shah SA, Tinkhauser G, Chen CC, Little S, Brown P. Parkinsonian tremor detection from subthalamic nucleus local field potentials for closed-loop deep brain stimulation. Annu Int Conf IEEE Eng Med Biol Soc. 2018;2018:2320-4. https://doi. org/10.1109/embc.2018.8512741

PMid:30440871

12. Murata J, Sawamura $Y$, Kitagawa M, Saito H, Kikuchi S, Tashiro K. Minimally invasive stereotactic functional surgery using an intravenous anesthetic propofol and applying image fusion and AtlasPlan. No To Shinkei. 2001;53(5):457-62. PMid: 11424357

13. Bahgat D, Magill ST, Berk C, McCartney S, Burchiel KJ. Thalamotomy as a treatment option for tremor after ineffective deep brain stimulation. Stereotact Funct Neurosurg. 2013;91(1):18-23. https://doi.org/10.1159/000342491 PMid:23154796

14. Israel Z, Hsu FP, Burchiel KJ. Is microelectrode recording necessary? Semin Neurosurg. 2001;12(2):169-74. Available from: http://www.thieme-connect.de.

15. Palur RS, Berk C, Schulzer M, Honey CR. A metaanalysis comparing the results of pallidotomy performed using microelectrode recording or macroelectrode stimulation. J Neurosurg. 2002;96(6):1058-62. https://doi.org/10.3171/ jns.2002.96.6.1058

PMid: 12066907

16. Kondziolka D, Bonaroti E, Baser S, Brandt F, Kim YS, Lunsford LD. Outcomes after stereotactically guided pallidotomy for advanced Parkinson's disease. J Neurosurg. 1999;90(2):197202. https://doi.org/10.3171/jns.1999.90.2.0197 PMid:9950488

17. Giller CA, Dewey RB, Ginsburg MI, Mendelsohn DB, Berk AM. Stereotactic pallidotomy and thalamotomy using individual variations of anatomic landmarks for localization. Neurosurgery. 1998;42(1):55-6. https://doi. org/10.1097/00006123-199801000-00011 PMid:9442504

18. Shannon KM, Penn RD, Kroin JS, Adler CH, Janko KA, York M, et al. Stereotactic pallidotomy for the treatment of Parkinson's disease. Efficacy and adverse effects at 6 months in 26 patients. Neurology. 1998;50(2):434-8. https://doi.org/10.1212/ wnl.50.2.434

PMid:9484368

19. Baron MS, Vitek JL, Bakay RA, Green J, McDonald WM, Cole SA, et al. Treatment of advanced Parkinson's disease by unilateral posterior GPi pallidotomy: 4-year results of a pilot study. Mov Disord. 2000;15(2):230-7. https://doi.org/10.1002/15318257(200003)15:2<230:aid-mds1005>3.0.co;2-u PMid: 10752571

20. Lozano AM, Lang AE, Galvez-Jimenez N, Miyasaki J, Duff J, 
Hutchinson WD, et al. Effect of GPi pallidotomy on motor function in Parkinson's disease. Lancet. 1995;346(8987):1383- 7. https:// doi.org/10.1016/s0140-6736(95)92404-3

PMid:7475819

21. Vitek JL, Bakay RA, Freeman A, Evatt M, Green J, McDonald W, et al. Randomized trial of pallidotomy versus medical therapy for Parkinson's disease. Ann Neurol. 2003;53(5):558-69. https:// doi.org/10.1002/ana.10517

PMid:12730989

22. de Bie RM, de Haan RJ, Nijssen PC, Rutgers AW, Beute GN, Bosch DA, et al. Unilateral pallidotomy in Parkinson's disease: A randomised, single-blind, multicentre trial. Lancet. 1999;354(9191):1665-9. https://doi.org/10.1016/ s0140-6736(99)03556-4

PMid:10568567

23. Jankovic J, Cardoso F, Grossman RG, Hamilton WJ. Outcome after stereotactic thalamotomy for parkinsonian, essential, and othertypes oftremor. Neurosurgery. 1995;37(4):680-6; discussion 686-7. https://doi.org/10.1097/00006123-199510000-00011 PMid:8559296

24. Schuurman PR, Bosch DA, Bossuyt PM, Bonsel GJ, van Someren EJ, de Bie RM, et al. A comparison of continuous thalamic stimulation and thalamotomy for suppression of severe tremor. N Engl J Med. 2000;342(7):461-8. https://doi. org/10.1056/nejm200002173420703

PMid: 10675426

25. Umemura A, Jaggi JL, Hurtig HI, Siderowf AD, Colcher $A$, Stern MB, et al. Deep brain stimulation for movement disorders: Morbidity and mortality in 109 patients. J Neurosurg. 2003;98(4):779-84. https://doi.org/10.3171/jns.2003.98.4.0779 PMid:12691402

26. Temel $Y$, Ackermans $L$, Celik $H$, Spincemaille $G H$, van der Linden C, Walenkamp GH, et al. Management of hardware infections following deep brain stimulation. Acta Neurochir (Wien). 2004;146(4):355-61; discussion 361. https://doi. org/10.1007/s00701-004-0219-2 PMid:15057529

27. Nijhawan SR, Banks SJ, Aziz TZ, Panourias I, Gregory R, Yianni $\mathrm{J}$, et al. Changes in cognition and health-related quality of life with unilateral thalamotomy for Parkinsonian tremor. J Clin Neurosci. 2009;16(1):44-50. https://doi.org/10.1016/j. jocn.2008.03.008

PMid:19019683

28. Terao $\mathrm{T}$, Takahashi $\mathrm{H}$, Yokochi $\mathrm{F}$, Taniguchi M, Okiyama $\mathrm{R}$, Hamada I. Hemorrhagic complication of stereotactic surgery in patients with movement disorders. J Neurosurg. 2003;98(6):1241-6. https://doi.org/10.3171/jns.2003.98.6.1241 PMid:12816271

29. Ben-Haim S, Asaad WF, Gale JT, Eskandar EN. Risk factors for hemorrhage during microelectrode-guided deep brain stimulation and the introduction of an improved microelectrode design. Neurosurgery. 2009;64(4):753-4. https://doi. org/10.1227/01.neu.0000339173.77240.34 PMid:19349834

30. de Bie RM, Schuurman PR, Esselink RA, Bosch DA,
Speelman JD. Bilateral pallidotomy in Parkinson's disease: A retrospective study. Mov Disord. 2002;17(3):533-8. https://doi. org/10.1002/mds.10090

PMid:12112203

31. Chung SJ, Hong SH, Kim SR, Lee MC, Jeon SR. Efficacy and safety of simultaneous bilateral pallidotomy in advanced Parkinson's disease. Eur Neurol. 2006;56(2):113-8. https://doi. org/10.1159/000095701

PMid: 16960451

32. York MK, Lai EC, Jankovic J, Macias A, Atassi F, Levin HS, et al. Short and long-term motor and cognitive outcome of staged bilateral pallidotomy: A retrospective analysis. Acta Neurochir (Wien). 2007;149(9):857-66; discussion 866. https:// doi.org/10.1007/s00701-007-1242-x

PMid: 17624489

33. Merello M, Starkstein S, Nouzeilles MI, Kuzis G, Leiguarda R. Bilateral pallidotomy for treatment of Parkinson's disease induced corticobulbar syndrome and psychic akinesia avoidable by globus pallidus lesion combined with contralateral stimulation. J Neurol Neurosurg Psychiatry. 2001;71(5):611-4. https://doi. org/10.1136/jnnp.71.5.611

PMid:11606671

34. Tir M, Devos D, Blond S, Touzet G, Reyns N, Duhamel A, et al. Exhaustive, one-year follow-up of subthalamic nucleus deep brain stimulation in a large, single-center cohort of parkinsonian patients. Neurosurgery. 2007;61(2):297-304; discussion 304-5. https://doi.org/10.1227/01.neu.0000285347.50028.b9 PMid: 17762742

35. Obeso JA, Olanow CW, Rodriguez-Oroz MC, Krack P, Kumar R, Lang AE. Deep-brain stimulation of the subthalamic nucleus or the pars interna of the globus pallidus in Parkinson's disease. N Engl J Med. 2001;345(13):956-63. https://doi.org/10.1056/ nejmoa000827

PMid: 11575287

36. Hamani C, Richter E, Schwalb JM, Lozano AM. Bilateral subthalamic nucleus stimulation for Parkinson's disease: A systematic review of the clinical literature. Neurosurgery. 2008;62 Suppl 2:863-74. https://doi.org/10.1227/01. neu.0000316288.75736.1c PMid:18596421

37. Krystkowiak P, Blatt JL, Bourriez JL, Duhamel A, Perina M, Blond $\mathrm{S}$, et al. Effects of subthalamic nucleus stimulation and levodopa treatment on gait abnormalities in Parkinson disease. Arch Neurol. 2003;60(1):80-4. https://doi.org/10.1001/ archneur.60.1.80

PMid: 12533092

38. Moro E, Scerrati M, Romito LM, Roselli R, Tonali P, Albanese A. Chronic subthalamic nucleus stimulation reduces medication requirements in Parkinson's disease. Neurology. 1999;53(1):85- 90. https://doi.org/10.1212/wnl.53.1.85 PMid: 10408541

39. Zhao G, Li Y, Shao M, Ding Y. A clinical analysis of L-dopa induced dyskinesia treated by posteroventral pallidotomy for Parkinson's disease. Zhonghua Wai Ke Za Zhi. 1999;37(8):482-4.

PMid:11829894

\section{Author Queries???}

AQ7: Kindly provide text part 


\section{Appendix}

\section{UNIFIED PARKINSON'S DISEASE RATING SCALE (UPDRS) I. MENTATION, BEHAVIOR, AND MOOD}

\section{Intellectual Impairment}

$0 .=$ None.

1. $=$ Mild. Consistent forgetfulness with partial recollection of events and no other difficulties.

2. = Moderate memory loss, with disorientation, and moderate difficulty handling complex problems. Mild but definite impairment of function at home with need of occasional prompting.

3. = Severe memory loss with disorientation for time and often to place. Severe impairment in handling problems.

4. $=$ Severe memory loss with orientation preserved to person only. Unable to make judgments or solve problems. Requires much help with personal care. Cannot be left alone at all.

\section{Thought Disorder (Due to dementia or drug intoxication)}

\section{$0 .=$ None.}

1. $=$ Vivid dreaming.

2. = "Benign" hallucinations with insight retained.

3. = Occasional to frequent hallucinations or delusions; without insight; could interfere with daily activities.

4. $=$ Persistent hallucinations, delusions, or florid psychosis. Not able to care for self.

\section{Depression}

1. $=$ Periods of sadness or guilt greater than normal, never sustained for days or weeks.

2. $=$ Sustained depression (1 week or more).

3. $=$ Sustained depression with vegetative symptoms (insomnia, anorexia, weight loss, and loss of interest).

4. $=$ Sustained depression with vegetative symptoms and suicidal thoughts or intent.

\section{Motivation/Initiative}

$0 .=$ Normal.

1. = Less assertive than usual; more passive.

2. $=$ Loss of initiative or disinterest in elective (nonroutine) activities.

3. $=$ Loss of initiative or disinterest in day to day (routine) activities.

4. $=$ Withdrawn, complete loss of motivation.

\section{ACTIVITIES OF DAILY LIVING (for both "on" and "off")}

\section{Speech}

$0 .=$ Normal.

1. $=$ Mildly affected. No difficulty being understood.

2. $=$ Moderately affected. Sometimes asked to repeat statements.

3. $=$ Severely affected. Frequently asked to repeat statements.

4. $=$ Unintelligible most of the time.

\section{Salivation}

$0 .=$ Normal.

1. = Slight but definite excess of saliva in mouth; may have nighttime drooling.

2. = Moderately excessive saliva; may have minimal drooling.

3. = Marked excess of saliva with some drooling.

4. $=$ Marked drooling, requires constant tissue or handkerchief.

\section{Swallowing}

$0 .=$ Normal.

1. $=$ Rare choking.

2. = Occasional choking.

3. = Requires soft food.

4. = Requires NG tube or gastrostomy feeding.

\section{Handwriting}
$0 .=$ Normal.
1. $=$ Slightly slow or small.
2. = Moderately slow or small; all words are legible.
3. = Severely affected; not all words are legible.
4. $=$ The majority of words are not legible. 


\section{Cutting food and handling utensils}

$0 .=$ Normal.

1. = Somewhat slow and clumsy, but no help needed.

2. = Can cut most foods, although clumsy and slow; some help needed.

3. = Food must be cut by someone, but can still feed slowly.

4. $=$ Needs to be fed.

\section{Dressing}

$0 .=$ Normal.

1. $=$ Somewhat slow, but no help needed.

2. = Occasional assistance with buttoning, getting arms in sleeves.

3. $=$ Considerable help required, but can do some things alone.

4. $=$ Helpless.

11. Hygiene

$0 .=$ Normal.

1. $=$ Somewhat slow, but no help needed.

2. $=$ Needs help to shower or bathe; or very slow in hygienic care.

3. = Requires assistance for washing, brushing teeth, combing hair, going to bathroom .

4. $=$ Foley catheter or other mechanical aids.

12. Turning in bed and adjusting bed clothes

$0 .=$ Normal.

1. = somewhat slow and clumsy, but no help needed.

2. = Can turn alone or adjust sheets, but with great difficulty.

3. = Can initiate, but not turn or adjust sheets alone.

4. $=$ Helpless.

13. Falling (unrelated to freezing)

$0 .=$ None.

1. $=$ Rare falling

2. = Occasionally falls, less than once per day.

3. = Falls an average of once daily.

4. $=$ Falls more than once daily.

\section{Freezing when walking}

$0 .=$ None.

1. = Rare freezing when walking; may have start hesitation .

2. = Occasional freezing when walking.

3. $=$ Frequent freezing. Occasionally falls from freezing.

4. $=$ Frequent falls from freezing.

\section{Walking}

$0 .=$ Normal.

1. = Mild difficulty. May not swing arms or may tend to drag leg.

2. = Moderate difficulty, but requires little or no assistance.

3. = Severe disturbance of walking, requiring assistance.

4. $=$ Cannot walk at all, even with assistance.

16. Tremor (Symptomatic complaint of tremor in any part of body.)
0 . = Absent.
1. = Slight and infrequently present.
2. = Moderate; bothersome to patient.
3. = Severe; interferes with many activities.
4. = Marked; interferes with most activities.

\section{Sensory complaints related to Parkinsonism}
0 . = None.
1. = Occasionally has numbness, tingling, or mild aching.
2. = Frequently has numbness, tingling, or aching; not distressing.
3. = Frequent painful sensations.
4. = Excruciating pain. 


\section{MOTOR EXAMINATION}

18. Speech

$0 .=$ Normal.

1. = Slight loss of expression, diction, and/or volume.

2. $=$ Monotone, slurred but understandable; moderately impaired.

3. = Marked impairment, difficult to understand.

4. $=$ Unintelligible.

\section{Facial Expression}

$0 .=$ Normal.

1. = Minimal hypomimia, could be normal "Poker Face".

2. = Slight but definitely abnormal diminution of facial expression

3. = Moderate hypomimia; lips parted some of the time.

4. $=$ Masked or fixed facies with severe or complete loss of facial expression; lips parted 1/4 inch or more.

\section{Tremor at rest (head, upper, and lower extremities)}

$0 .=$ Absent.

1. $=$ Slight and infrequently present.

2. = Mild in amplitude and persistent. Or moderate in amplitude, but only intermittently present.

3. = Moderate in amplitude and present most of the time.

4. $=$ Marked in amplitude and present most of the time.

\section{Action or Postural Tremor of hands}

$0 .=$ Absent.

1. = Slight; present with action.

2. = Moderate in amplitude, present with action.

3. = Moderate in amplitude with posture holding as well as action.

4. $=$ Marked in amplitude; interferes with feeding.

22. Rigidity (Judged on passive movement of major joints with patient relaxed in sitting position. Cogwheeling to be ignored.)

$0 .=$ Absent.

1. $=$ Slight or detectable only when activated by mirror or other movements.

2. = Mild to moderate.

3. = Marked, but full range of motion easily achieved.

4 = Severe, range of motion achieved with difficulty.

\section{Finger taps (Patient taps thumb with index finger in rapid succession.)}

$0 .=$ Normal.

1. = Mild slowing and/or reduction in amplitude.

2. = Moderately impaired. Definite and early fatiguing. May have occasional arrests in movement.

3. = Severely impaired. Frequent hesitation in initiating movements or arrests in ongoing movement.

4. = Can barely perform the task.

\section{Hand movements (Patient opens and closes hands in rapid succession.)}

$0 .=$ Normal.

1. $=$ Mild slowing and/or reduction in amplitude.

2. = Moderately impaired. Definite and early fatiguing. May have occasional arrests in movement.

3. $=$ Severely impaired. Frequent hesitation in initiating movements or arrests in ongoing movement.

4. $=$ Can barely perform the task.

25. Rapid Alternating Movements of Hands (Pronation-supination movements of hands, vertically and horizontally, with as large an amplitude as possible, both hands simultaneously.)

$0 .=$ Normal.

1. = Mild slowing and/or reduction in amplitude.

2. = Moderately impaired. Definite and early fatiguing. May have occasional arrests in movement.

3. $=$ Severely impaired. Frequent hesitation in initiating movements or arrests in ongoing movement.

4. $=$ Can barely perform the task . 
26. Leg agility (Patient taps heel on the ground in rapid succession picking up entire leg. Amplitude should be at least 3 inches.)

$0 .=$ Normal.

1. $=$ Mild slowing and/or reduction in amplitude.

2. = Moderately impaired. Definite and early fatiguing. May have occasional arrests in movement.

3. = Severely impaired. Frequent hesitation in initiating movements or arrests in ongoing movement.

4. = Can barely perform the task.

27. Arising from chair (Patient attempts to rise from a straight-backed chair, with arms folded across chest.)

$0 .=$ Normal.

1 = Slow; or may need more than one attempt.

2. = Pushes self-up from arms of seat.

3. = Tends to fall back and may have to try more than one time, but can get up without help.

4. $=$ Unable to arise without help.

\section{Posture}

$0 .=$ Normal erect.

1. = Not quite erect, slightly stooped posture; could be normal for older person.

2. = Moderately stooped posture, definitely abnormal; can be slightly leaning to one side.

3. = Severely stooped posture with kyphosis; can be moderately leaning to one side.

4. $=$ Marked flexion with extreme abnormality of posture.

\section{Gait}

$0 .=$ Normal.

1. $=$ Walks slowly, may shuffle with short steps, but no festination (hastening steps) or propulsion.

2. = Walks with difficulty, but requires little or no assistance; may have some festination, short steps, or propulsion.

3. = Severe disturbance of gait, requiring assistance.

4. = Cannot walk at all, even with assistance.

30. Postural stability (Response to sudden, strong posterior displacement produced by pull on shoulders while patient erect with eyes open and feet slightly apart. Patient is prepared.)

$0 .=$ Normal.

1. $=$ Retropulsion, but recovers unaided.

2. = Absence of postural response; would fall if not caught by examiner.

3. $=$ Very unstable, tends to lose balance spontaneously.

4. $=$ Unable to stand without assistance.

31. Body bradykinesia and hypokinesia (Combining slowness, hesitancy, decreased armswing, small amplitude, and poverty of movement in general.)

0 . $=$ None.

1. = Minimal slowness, giving movement a deliberate character; could be normal for some persons. Possibly reduced amplitude.

2. = Mild degree of slowness and poverty of movement which is definitely abnormal. Alternatively, some reduced amplitude.

3. = Moderate slowness, poverty or small amplitude of movement.

4. = Marked slowness, poverty or small amplitude of movement.

\section{COMPLICATIONS OF THERAPY (In the past week)}

\section{A. DYSKINESIAS}

32. Duration: What proportion of the waking day are dyskinesias present? (Historical information.)

$0 .=$ None

1. $=1-25 \%$ of day.

2. $=26-50 \%$ of day.

3. $=51-75 \%$ of day.

4. $=76-100 \%$ of day. 
33. Disability: How disabling are the dyskinesias? (Historical information; may be modified by office examination.)

$0 .=$ Not disabling.

1. = Mildly disabling.

2. = Moderately disabling.

3. $=$ Severely disabling.

4 = Completely disabled.

34. Painful dyskinesias: How painful are the dyskinesias?

$0 .=$ No painful dyskinesias.

1. $=$ Slight.

2. $=$ Moderate.

3. $=$ Severe

4. $=$ Marked.

35. Presence of early morning dystonia (Historical information.)

$0 .=$ No.

1. $=$ Yes.

B. Clinical fluctuations

36. Are "off" periods predictable?

$0 .=$ No

1. $=$ Yes

37. Are "off" periods unpredictable?

$0 .=$ No

1. $=$ Yes

38. Do "off" periods come on suddenly, within a few seconds?

$0 .=$ No

1. $=$ Yes

39. What proportion of the waking day is the patient "off" on average?
$0 .=$ None
1. $=1-25 \%$ of day.
2. $=26-50 \%$ of day.
3. $=51-75 \%$ of day.
4. $=76-100 \%$ of day.

C. Other complications

40. Does the patient have anorexia, nausea, or vomiting?

$0 .=$ No

1. $=$ Yes

41. Any sleep disturbances, such as insomnia or hypersomnolence?

$$
0 .=\text { No }
$$

1. $=$ Yes

42. Does the patient have symptomatic orthostasis?

(Record the patient's blood pressure, height and weight on the scoring form)

$$
\begin{aligned}
& \text { 0. }=\text { No } \\
& \text { 1. }=\text { Yes }
\end{aligned}
$$

\section{MODIFIED HOEHN AND YAHR STAGING}

STAGE $0=$ No signs of disease.

STAGE 1 = Unilateral disease.

STAGE 1.5 = Unilateral plus axial involvement.

STAGE 2 = Bilateral disease, without impairment of balance.

STAGE 2.5 = Mild bilateral disease, with recovery on pull test.

STAGE 3 = Mild to moderate bilateral disease; some postural instability; physically independent.

STAGE 4 = Severe disability; still able to walk or stand unassisted.

STAGE 5 = Wheelchair bound or bedridden unless aided. 


\section{SCHWAB AND ENGLAND ACTIVITIES OF DAILY LIVING SCALE}

$100 \%=$ Completely independent. Able to do all chores without slowness, difficulty or impairment. Essentially normal. Unaware of any difficulty.

$90 \%=$ Completely independent. Able to do all chores with some degree of slowness, difficulty and impairment. Might take twice as long. Beginning to be aware of difficulty.

$80 \%=$ Completely independent in most chores. Takes twice as long. Conscious of difficulty and slowness.

$70 \%=$ Not completely independent. More difficulty with some chores. Three to four times as long in some. Must spend a large part of the day with chores.

$60 \%=$ Some dependency. Can do most chores, but exceedingly slowly and with much effort. Errors; some impossible.

$50 \%=$ More dependent. Help with half, slower, etc. Difficulty with everything.

$40 \%=$ Very dependent. Can assist with all chores, but few alone.

$30 \%=$ With effort, now and then does a few chores alone or begins alone. Much help needed.

$20 \%=$ Nothing alone. Can be a slight help with some chores. Severe invalid.

$10 \%=$ Totally dependent, helpless. Complete invalid.

$0 \%=$ Vegetative functions such as swallowing, bladder and bowel functions are not functioning. Bedridden.

\section{MMSE}

Patient's Name:

Date:

Instructions: Score one point for each correct response within each question or activity.

\begin{tabular}{|c|c|c|}
\hline Maximum s0.core & Patient's score & Questions \\
\hline \multirow[t]{2}{*}{05} & & "What is the year? Season? Date? Day? Month?" \\
\hline & & تعرف النهاردة يوم في الأسبو ع؟ الثناريخ؟ الشهر ؟ صيف ولا شتاء؟ سنة كام؟ \\
\hline \multirow[t]{2}{*}{5} & & "Where are we now? State? County? Town/city? Hospital? Floor?" \\
\hline & & احنا فين دلوقتي؟ اسم المستشفى؟ الدور الكام؟ المدينة؟ المحافظة؟ الدولة؟ \\
\hline \multirow[t]{2}{*}{3} & & $\begin{array}{l}\text { The examiner names three unrelated objects clearly and slowly, then the instructor asks the patient to name all three of them. The patient's } \\
\text { response is used for scoring. The examiner repeats them until patient learns all of them, if possible. }\end{array}$ \\
\hline & & كرسي - وردة - فنجان \\
\hline \multirow[t]{4}{*}{5} & & "I would like you to count backward from 100 by sevens." $(93,86,79,72,65, \ldots)$ \\
\hline & & Alternative: "Spell WORLD backwards." (D-L-R-O-W) \\
\hline & & ناقص 7 كامج؟ ونكمل معاه 100 \\
\hline & & أيام الأسبوع بالعكس او الشهور بالعكس \\
\hline \multirow[t]{2}{*}{3} & & $\begin{array}{l}\text { "Earlier I told you the names of three things. Can you tell me what } \\
\text { those were?" }\end{array}$ \\
\hline & & 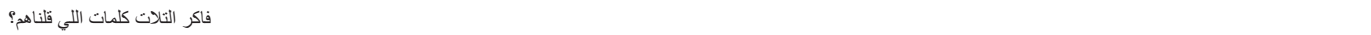 \\
\hline 2 & & 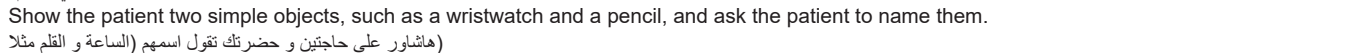 \\
\hline 1 & & "Repeat the phrase: 'No ifs, ands, or buts."' \\
\hline \multirow[t]{2}{*}{3} & & 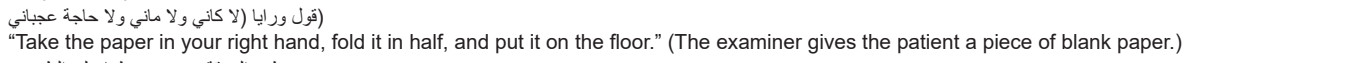 \\
\hline & & " طبق الورقة مرتين و حطها على الطربيزة \\
\hline 1 & & 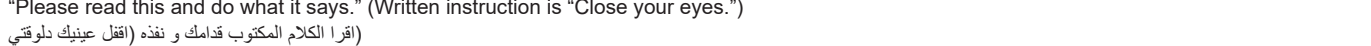 \\
\hline 1 & & $\begin{array}{l}\text { "Make up and write a sentence about anything." (This sentence must } \\
\text { contain a noun and a verb.) } \\
\text { قولي جملة مفيدة }\end{array}$ \\
\hline 1 & & $\begin{array}{l}\text { "Please copy this picture." (The examiner gives the patient a blank piece of paper and asks him/her to draw the symbol below. All } 10 \text { angles must be } \\
\text { present and two must intersect.) } \\
\text { نرسم رسمة ونطلب من المريض تقليها }\end{array}$ \\
\hline 30 & & Total \\
\hline
\end{tabular}

